\title{
Explaining the Model of Cultural Planning of Urban Parks
}

\author{
Leila Medghalchi ${ }^{{ }^{*}}$, Morteza Mirgholami ${ }^{2}$, Mehdi Nilipour ${ }^{3}$ \\ 1 Assistant Professor, Faculty of Architecture and Urbanism, Tabriz Islamic Art University, Tabriz, Iran. \\ 2 Associate Professor, Faculty of Architecture and Urbanism, Tabriz Islamic Art University, Tabriz, Iran. \\ $3 \mathrm{PhD}$ Candidate in Islamic Urbanism, Faculty of Architecture and Urbanism, Tabriz Islamic Art University, Tabriz, Iran. \\ (Received 22 Oct 2020, Accepted 23 Jan 2021)
}

In Iran, urban parks are one of the most important urban spaces. In the most recent decades, with the changes that have taken place in the Iranian way of life, social interactions and the type of activity of people in urban parks have changed. What needs to be considered in this regard is how to plan for urban parks for the use of different age and sex groups. To do that, you need to discover the cultural resources of urban parks and the discovery of cultural resources is possible through cultural planning. Cultural planning has become one of the key approaches in urban planning. Cultural planning is a new placebased approach within which urban parks designers, planners and managers view culture. Cultural planning uses cultural resources in urban planning and urban parks include many types of cultural resources; therefore, it seems urban parks are one of the best places to be selected for cultural planning. Cultural planning uses cultural resources to enhance urban and community development. Cultural resources as the core part of cultural planning play a key role to form the pattern of events in urban parks. Cultural resources in urban parks can be categorized as urban parks, visible elements, and events (tangible resources); and meanings and associations (intangible resources). Elements and events present in urban parks are capable of evoking meanings and associations for them and lead them to form activities and events. These elements consist of man-made elements, natural elements, sensory elements, humans, animals and plants. Urban parks designers, planners and managers need to consider these elements and related events as tangible cultural resources that can be altered, replaced or reinforced. The tangible cultural resources in urban parks can lead to evoke meanings and associations for users as intangible cultural resources. The present study sought to find a model of cultural planning of urban parks. Interpretive methods have been used to study the theoretical foundations and the empirical background and to examine the phenomenon of urban park, cultural resources and the pattern of its events. Finally, the proposed model is presented. The findings show that the cultural planning of urban parks includes various stages that need to be done in order to achieve the desired result. The first step is to choose the field of study. It is necessary to choose an urban park that has enough variety of elements and events, as well as meanings and associations for users. In the second step, cultural mapping, the cultural resources in the studied urban park are identified, including tangible cultural resources (elements and events) and intangible cultural resources (meanings and associations). In the third step, cultural assessment, the approach of urban park managers and policy makers towards cultural resources is analyzed and in the final step, creative methods are used to make optimal use of cultural resources to improve the urban park. First, the hierarchical method of urban park facilities is used to ensure that the facilities of the parks are adequate and appropriate to the needs of the community. Later on, the range of recreational opportunities appropriate to cultural resources and the diversity of users in terms of age, gender, ethnicity, language and diversity of cultural resources are presented. Conflicts, issues and problems will then be identified. For conflicts, major issues and problems that require immediate action, the approach of issues (categories) is used, and for conflicts, minor issues and problems, the organic or gradual approach is used. To promote the health, welfare and well-being of users, a community development approach is used that can make optimal use of cultural resources to empower the community, increase the sense of identity and sense of belonging to the parks' users.

Keywords: Cultural planning, cultural resources, urban parks.

${ }^{*}$ Corresponding author. E-mail: medghalchi@tabriziau.ac.ir

Copyright(C) 2020, the Authors / This open-access article is published under the terms of the Creative Commons AttributionNonCommercial 4.0 International License which permits Share (copy and redistribute the material in any medium or format) and Adapt (remix, transform, and build upon the material) under the Attribution-NonCommercial .terms 


\title{
تبيين الكوى برنامهريزى فر هنكى بوستانهاى شهرى"
}

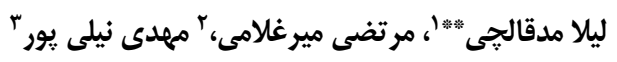

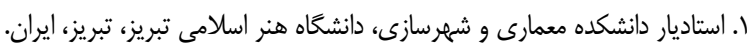

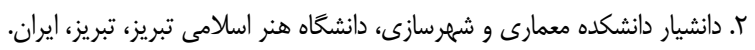

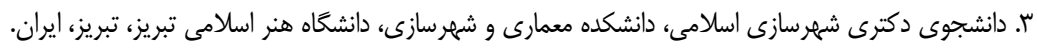

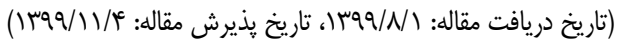

بوستانهاى شهرى يكى از مهمترين فضاهاى شهرى هستند. براى برنامهريزى بوستانهاى شهرى جهت استفاده انواع

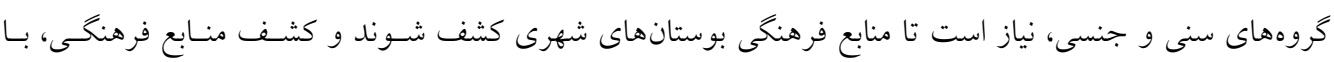

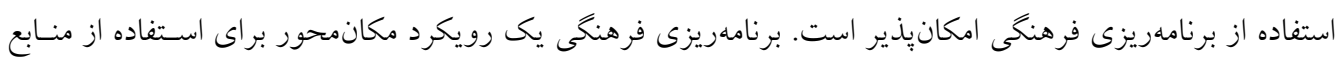

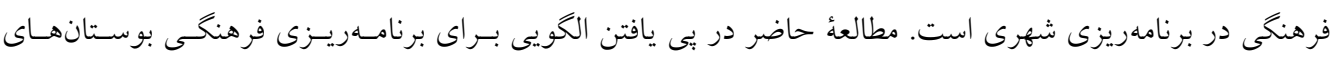

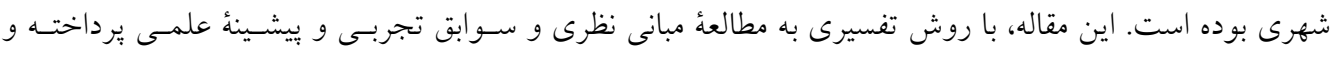

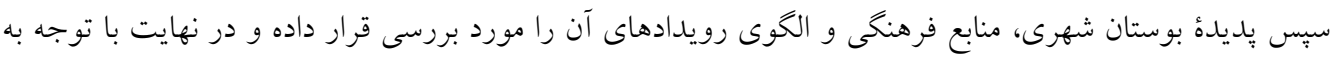

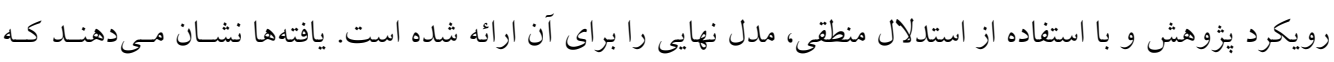

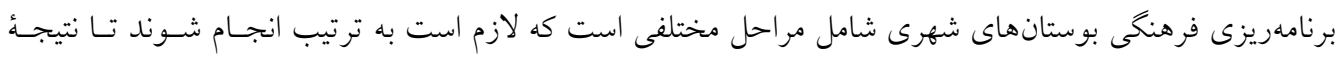

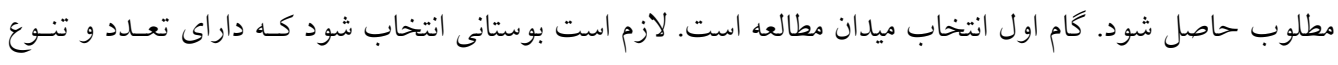

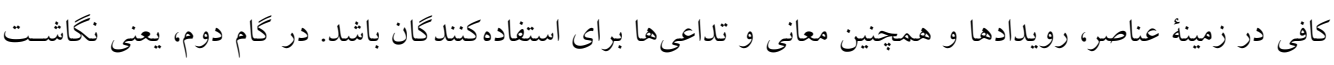

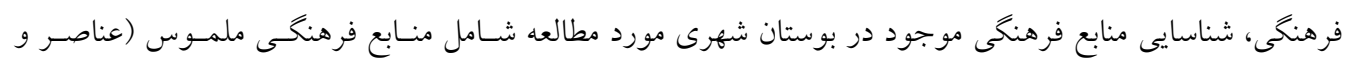

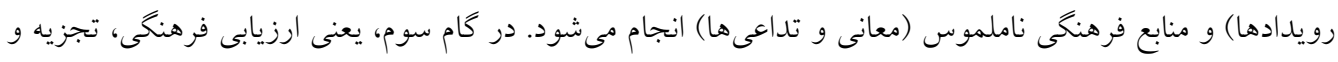

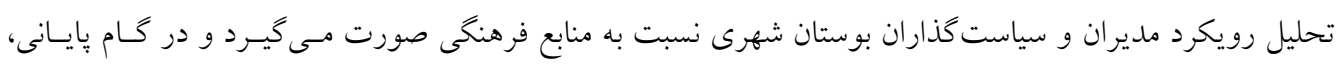

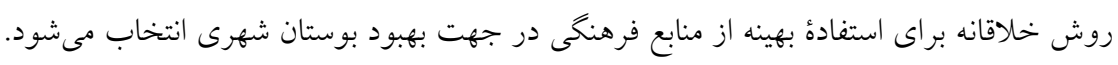

وازَّان كليدى

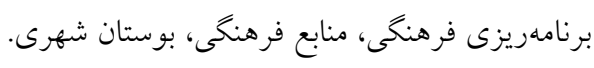

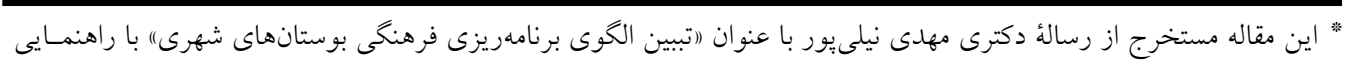

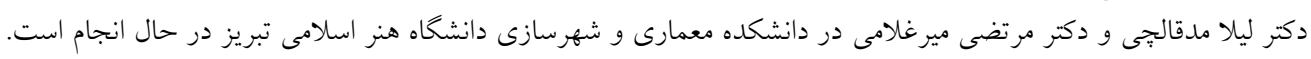

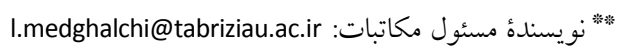


اما در يكى دو دهأ اخير، حضور بانوان در فضـاهاى عمـومى

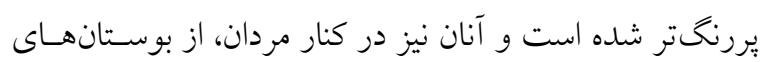

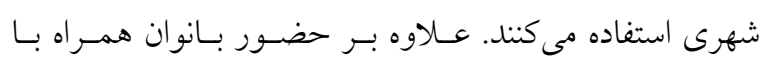

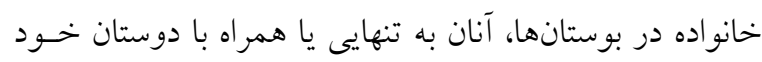
نيز به فعاليت در اين بوستانها مى يردازند.

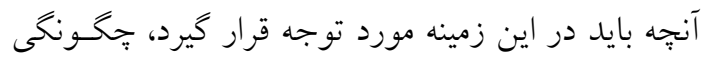
برنامهريزى براى بوسـتانهـاى شـهرى جهـت اسـتفاده انـواع

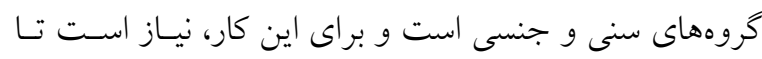
نسبت به علايق و منافع فرهنكى افرادى كه از اين بوسـتانهـا

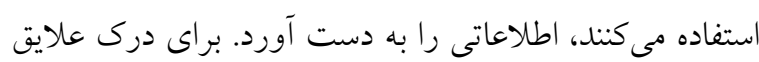

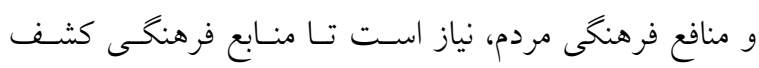

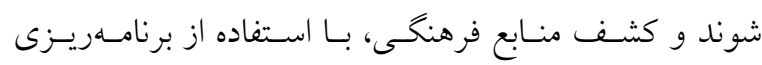
فرهنخى امكانيذير است. برنامهريزى فرهنخى يـك رويكـرد

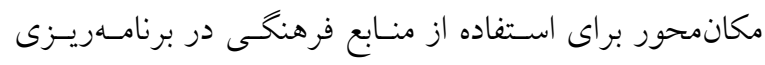

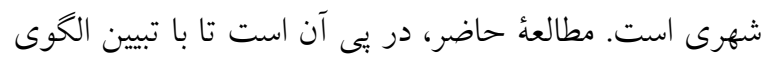
برنامهريزى فرهنكى بوستانهاى شهرى، با حفظ يا تغيير منابع

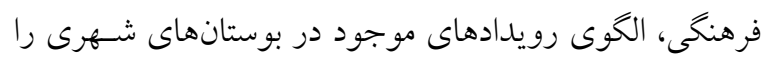
برنامهريزى كند.

خارج از زارجوب زندگى اجتماعى وجود داشته باشـــ و مـا

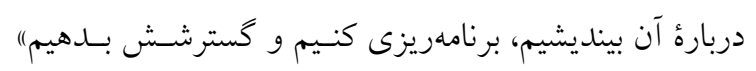

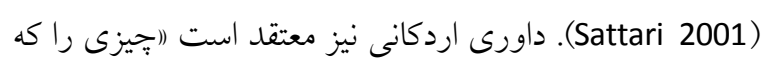

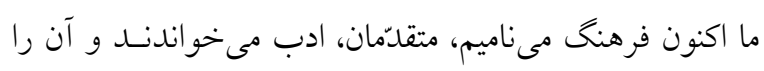

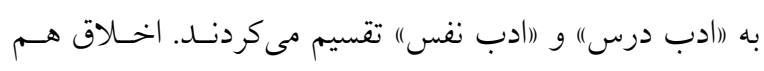
جزئى از ادب نفس بود و فرهنگ نه فقـط در مقابـل اخـالاق

قرار داشت، بلكه شامل آن بوده) (Davari Ardakani 2008). زرلانگ (Zerlang 2005) اشاره مى كند كه مفهوم فرهنخ در قرن نوزدهم شكل كرفته است. در اين قـرن، دو نويسـنده بزرگ، دو كونه مفهوم فرهنگ را مطرح كردند. در سال 1 119

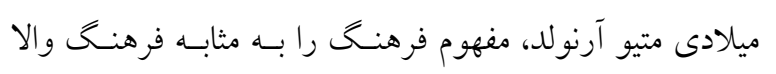
و در سال (High Culture) مثابه فرهنگ عامه (Popular Culture) مطرح كردند. بنـابراين
بوستانها به عنوان عمدهترين فضاى سبز شهرى نقسش بسـيار مهمى در زندگى اجتماعى و مـر اودات فرهنخسى شهرنشـينان

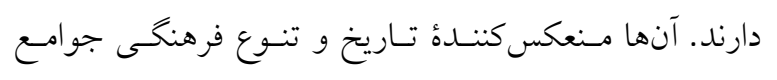

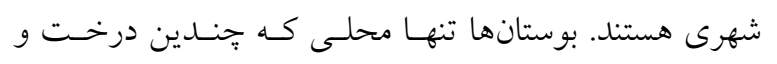

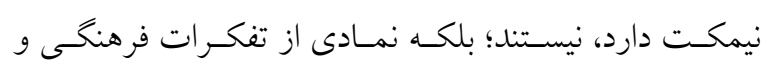
اجتماعى يك جامعـه محسـوب مسىشـوند. از سـوى ديخــ، افزايش شتاب زندگى مدرن شهرى منجـر بـه كـاهش تعامـل ئل

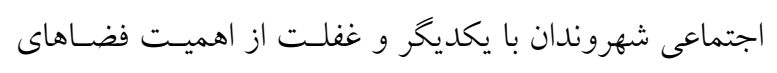
عمومى از جمله بوستانها به عنوان بسترى براى اين تعاملات

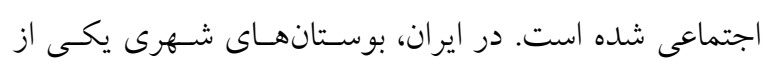

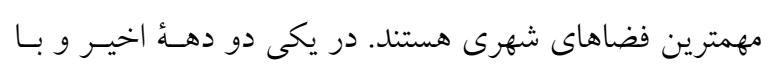

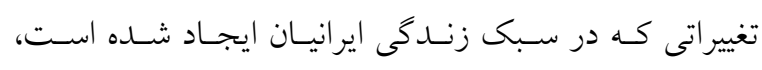

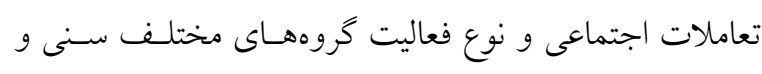
جنسى در بوستانهاى شهرى دجهار تحول شدهاند. بـهـ عنـوان

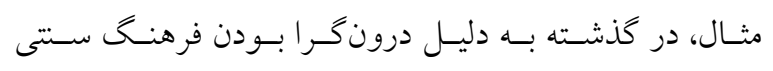

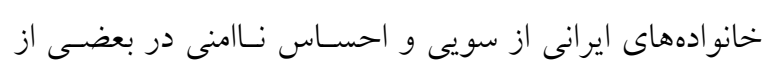

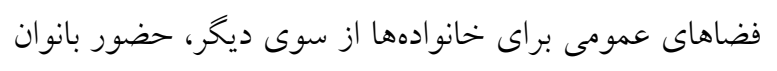

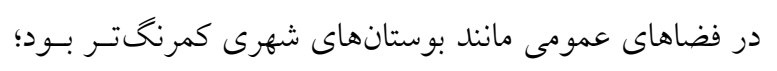

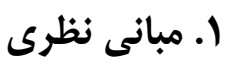

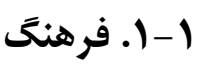

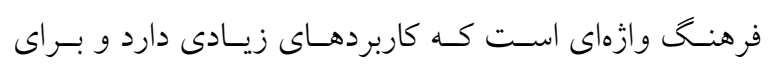

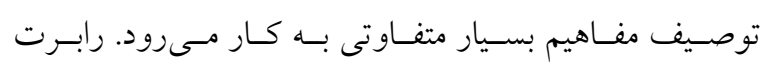

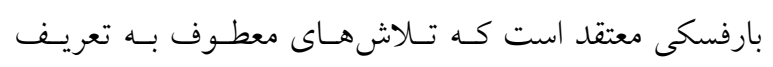

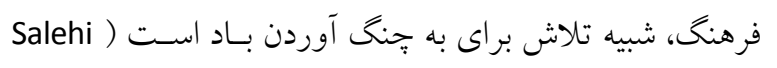

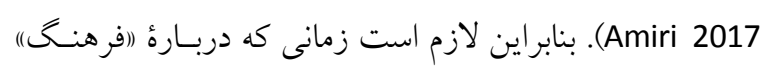

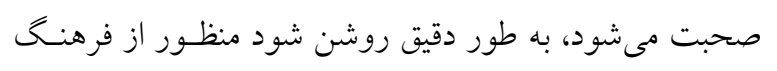
جيست. به نظر مىرسد در ايران تا زمان تجدد، بحث فرهنگ به عنوان موضوع جدى مورد بحث قرار نخرفته است. در ايسن زمينه جلال ستارى معتقد است: (تا بيش از دوران تجـدد، مـا

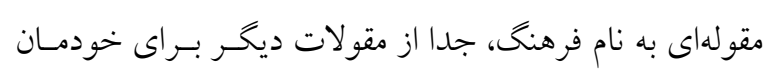

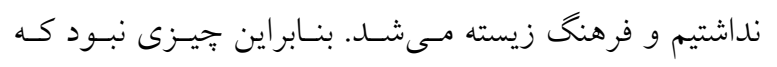


معنايى و تفسيرى كه از دنياى خارجى دارنـد، شـيوه زنــكى خود را انتخاب مى كنند. مفهوم كليدى براى كشف علت كنشهـا و واكسنشهـاى

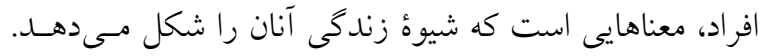

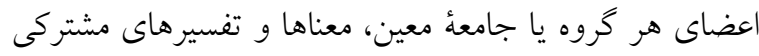

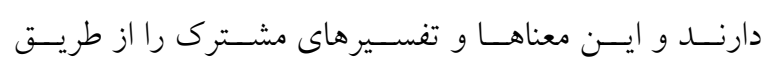

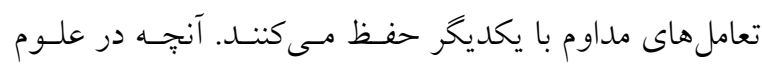

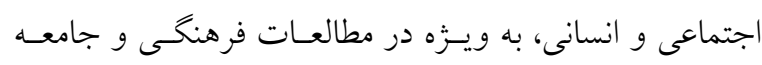

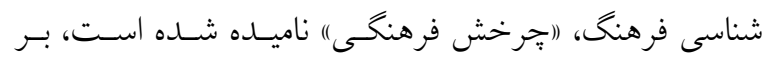

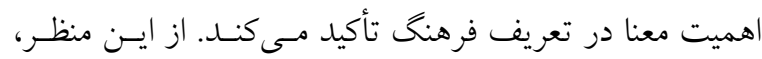

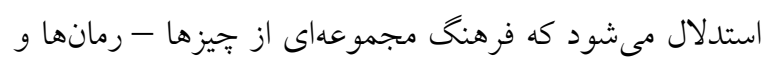

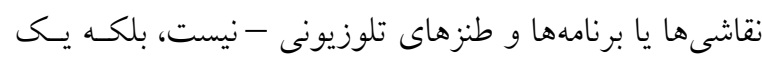

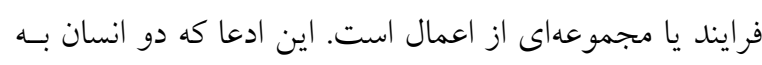

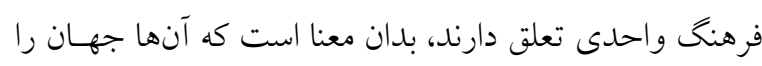

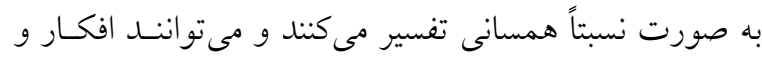

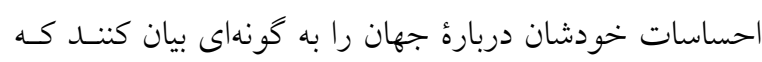

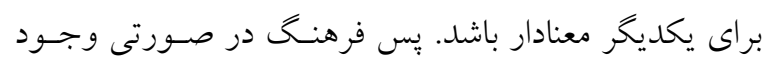

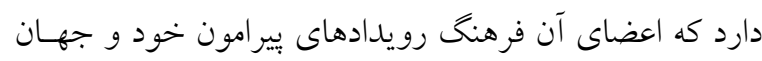

را به صورتهاى همسانى درك و فهم كنند (Hall 2017).

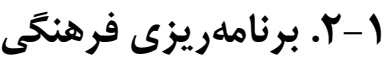

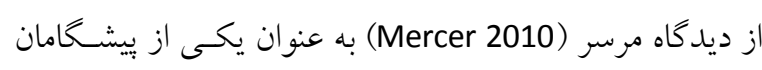
مطالعات برنامهريزى فرهنكى، اين نوع برنامهريزى را (استفاده

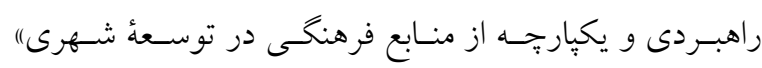

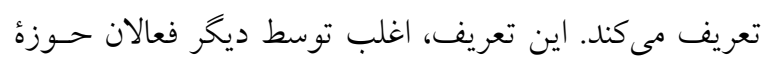

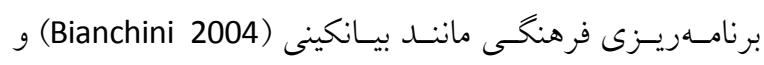

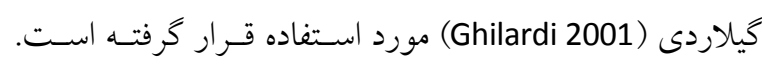

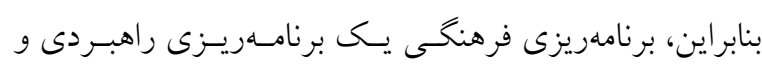

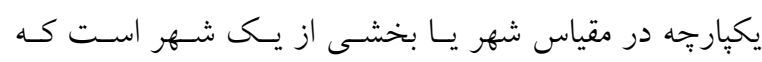

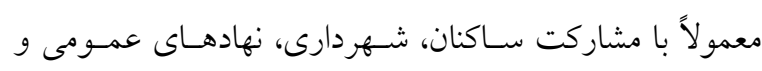

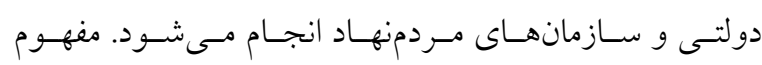

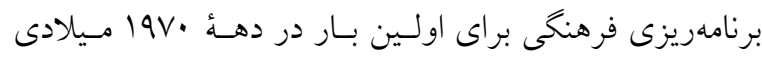

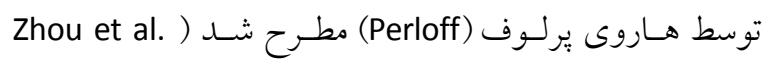

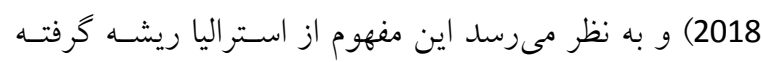

بحث بيرامون جِكونخى تلقى از فرهنگ از همـان زمـان آغـاز

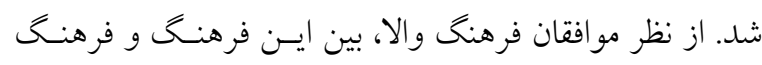

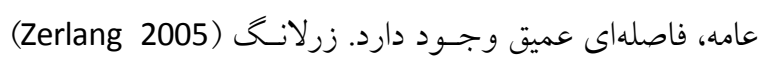

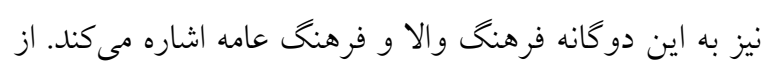

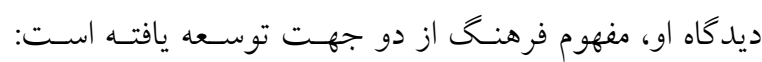

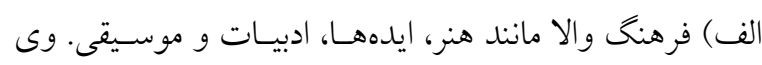

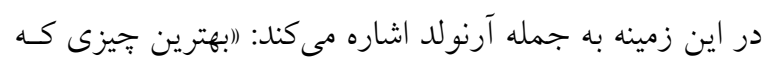

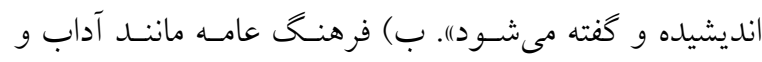

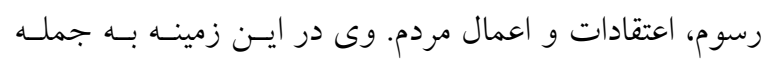
تيلور اشاره مى كند: (اشيوه كلى زندكى).

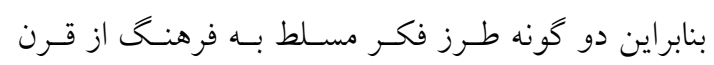

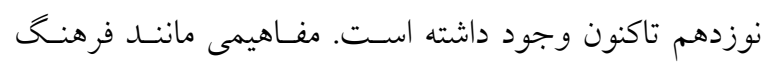

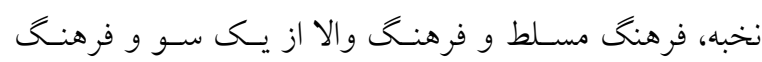

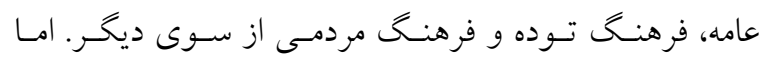

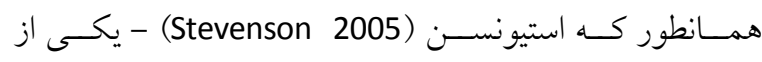

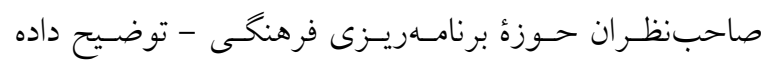
است، مىتوان فرهنگ را به كونهاى تعريـف كـرد كـه امكـان

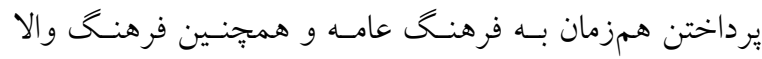

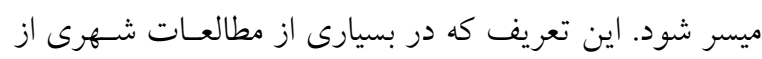

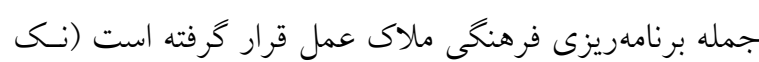

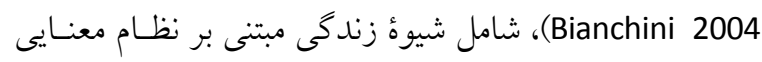

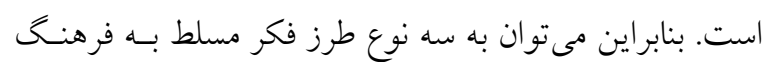

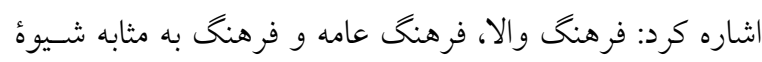
زندكى مبتنى بر نظام معنايى.

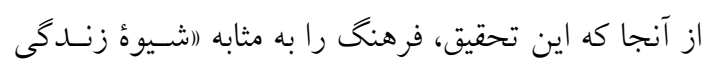

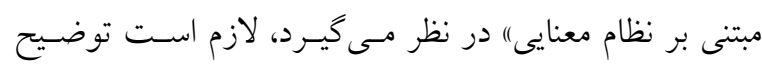

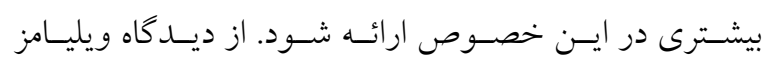

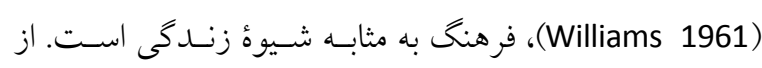

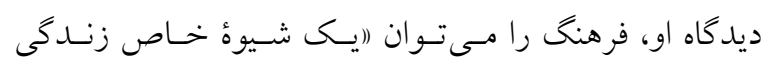

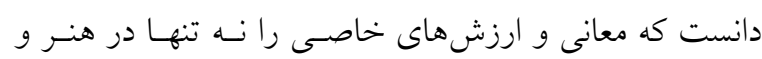
آموزش، بلكه در نهادهـا و رفتارهـاى عـادى بيـان مسى كنــد). مانـك، وينسـليد و سـينكلر ( Monk, Winslade, Sinclair

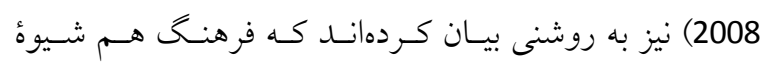
زندگى و هم شيوهُ تفسير زندكى است. افراد با توجه به نظسام 


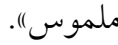
از آنجا كه مطالعهُ حاضر، فرهنخ را شيوهُ زنـدكى مبتنى

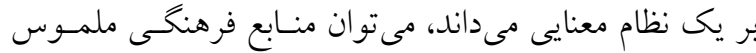
يك مكان را شامل عناصر و رويدادهاى قابل مشاهده دانستـ

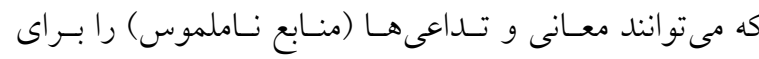
كاربران آن مكان برانخيزند.

\section{1-"-1. منابع فرهنكى ملموس}

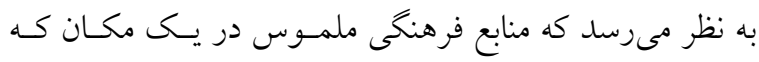

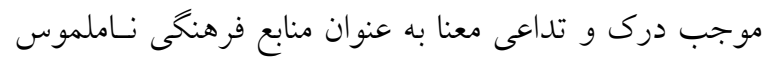
مىشوند شامل عناصر و رويدادهايى هستند كه در آنها مكان وجود دارد. عناصر شامل عناصر انسان ساخت، عناصر حسى، عناصر طبيعى، گياهان، حيوانات و انسانها است. اين عناصـر از طريق تركيب كيفيتهاى ادراكى، موجب مىشـوند تــاعى معنا صورت كيرد. تداعى معنا از طريق اين عناصر، مسىتوانـد

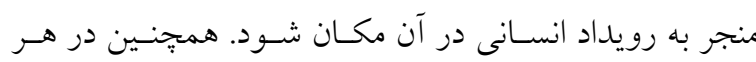

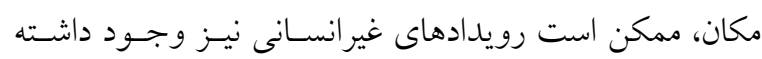

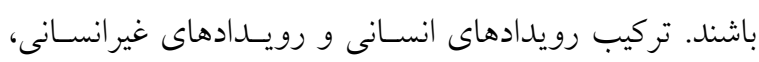

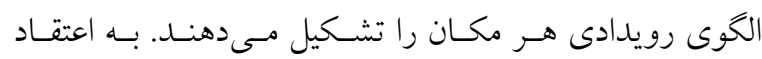

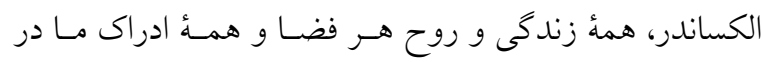

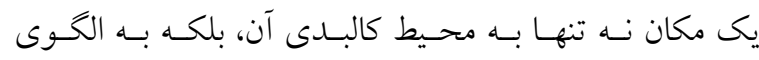
رويدادهايى بستخى دارد كه در آن جا رخ مسىدهـد. او تأكيــ

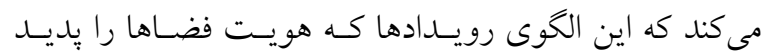

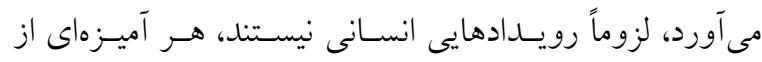

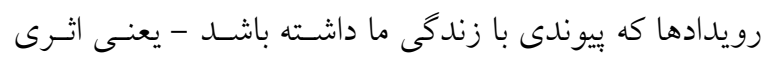
واقعى و فيزيكى بر مـا داشـته باشـــ - بـــر زنـدكى مـا تـأثير

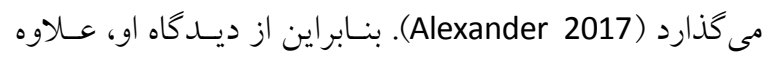
بــر عناصـر موجــود در يـك مكــان، رويــادهاى انسـانى و و غيرانسانى نيز موجب درك و تداعى معنا مىشوند و به عنوان منابع فرهنكى ملموس عمل مى كنند. جدول ا منابع فرهنخى مئى ملموس در مكان را نشان مى دهد.

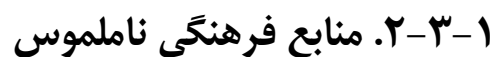

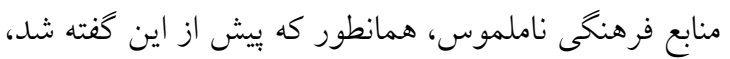

است (Fitzpatrick 2009). برنامهريـزى فرهنگـى متفـاوت از سياست كذارى فرهنكى است. آنجهه تـاكنون در ايـران مـلاكى عمل بوده، برنامهريزى فرهنگ يا سياست گذارى فرهنخى يـا

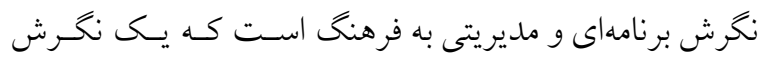

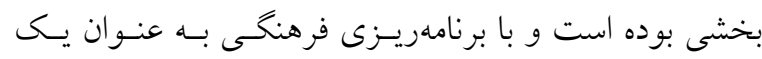

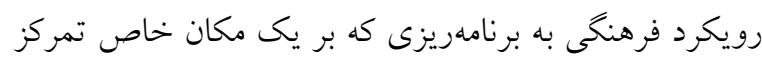
دارد، كاملاً متغاوت است. تصن.

مرسر (Mercer 2010) بــه عنـوان يكسى از بيشـحامان در اين حوزه، در تعريف خود از برنامهريزى فرهنكى بــر (امنـابع

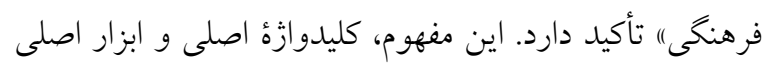

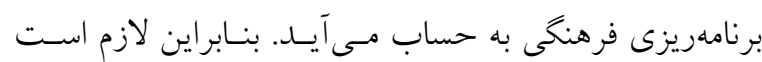

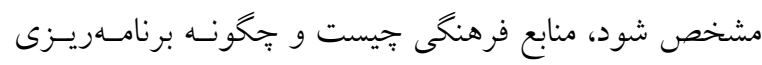
فرهنگى از آن بهره مى گيرد.

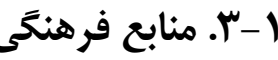

به كفته كينگ (King 2011)، (النابع فرهنكى همهُ جنبه هاى كالبدى و فراكالبدى محيط محسوب مىشوند كه انسانها و جوامع براى آنها به دلايلى كه با فرهنگ ارتباط دارد، ارزش قائل هستند). همانطور كه توسط برلى (Perley 2011) بيان شده، هريسون (Harrison 2007) منابع فرهنكى را به دو دسته تقسيم مى كند: ملموس (مصنوع، مادى) و ناملموس (مفاهيم، انديشهاى). منابع فرهنكى ملموس نه تنها محيطها و اشياء ساخته شده توسط انسان (ساختمانها، مكانها، محلات، اشياء متحرى بزرگ مانند قطار، كشتى، هواييما يا مصنوعات كوجّتر مانند ابزار، اسلحه و يادگارىها را شامل مىشود) (Morse-Kahn 2011)، بلكه محيطهاى طبيعى زنده و بى جان مانند سنگ، خاك، آب و به ويزه كياهان و حيوانات

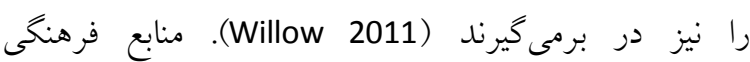

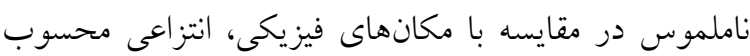

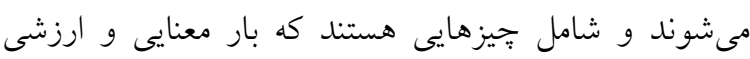
دارند (Ellis 2011). همانطور كه اليس اظهار مى كند، (منابع فرهنگى ناملموس غالباً با منابع فرهنگى ملموس مرتبط

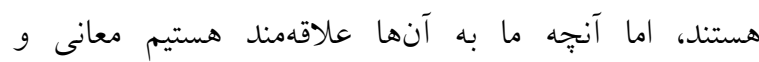

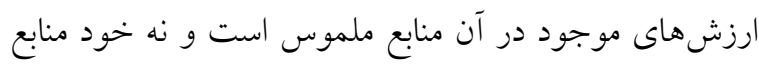


جدول ا: منابع فرهنكى ملموس در مكان

Table 1: Tangible cultural resources in the place

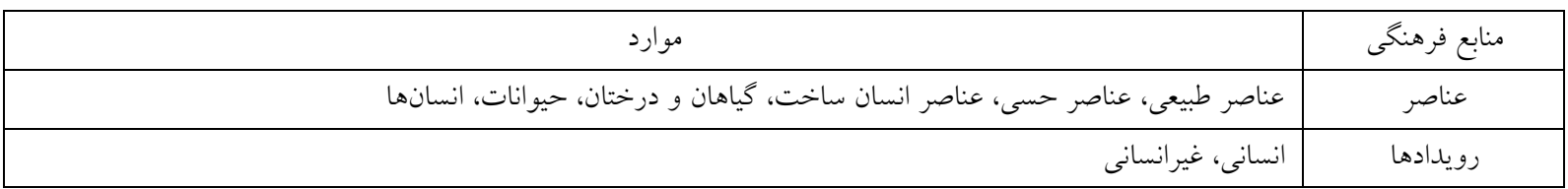

با مكان آنها تمايل دارد (Relph 1976). دويتو (DeVito 2012) معانى را به دو دستهُ معانى صريح و معــانى ضــمنى (Denotative)

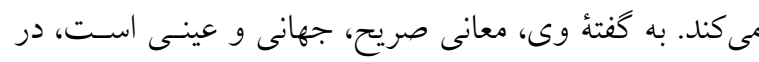

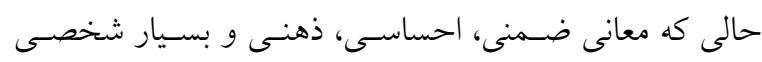

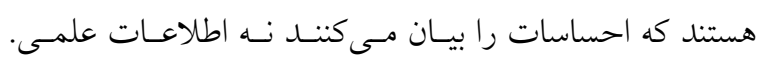
رضازاده نيز به اين دو سطح معنا اشـاره كـرده اسـت. معسانى

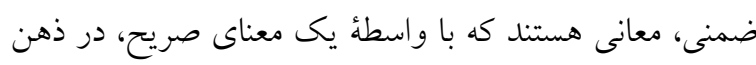

تداعى مىشوند (Rezazadeh 2004). اكنون سئوال اين است كه جِّونه معانى ادراك مىشوند.

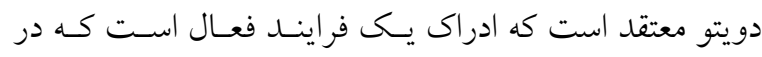

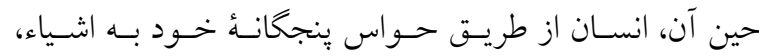

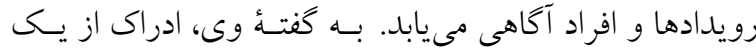

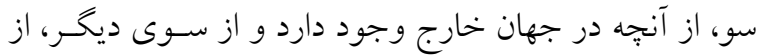
تجربيـات، خواسـتهــا، نيازهـا و تمــايلات، عشـق و نفــرت

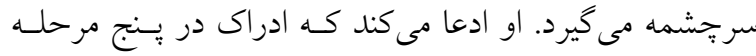
انجام مىشود: تحريك (حس كردن و توجه به يكى محـرى)،

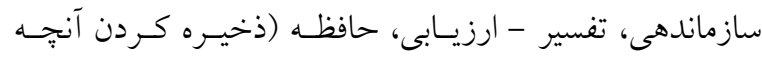
درى مى شود) و به ياد آوردن (دسترسى به اطلاعـات ذخيـيره

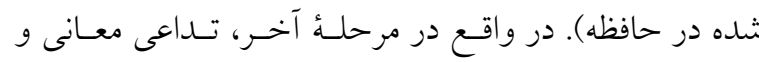
جيزها اتفاق مىافتد (DeVito 2012).

\section{r. فرايند ادراك و تداعى معنا در بوستان هاى

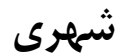

همانطور كه قبلاً كفته شد، عناصر بوستانهاى شهرى معانى و

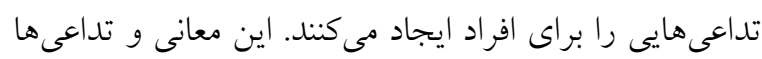

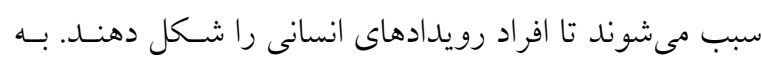

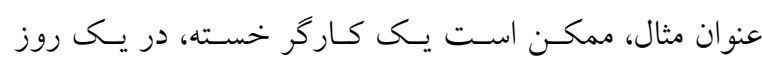

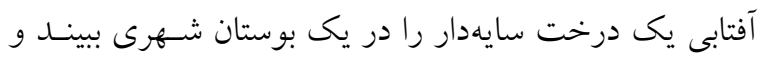

شامل معانى و تداعىها اسـت. بنـابراين لازم اسـت در مـورد

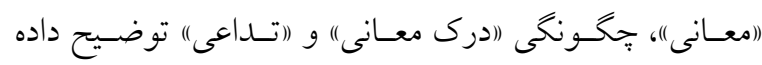

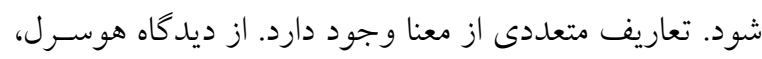

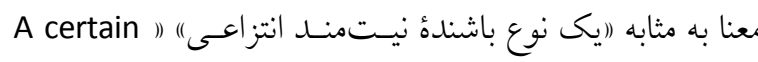
(sort of abstract, intensional entity (Smith and Mclntyre 1982) بنـابراين لازم اسـت مفـاهيم

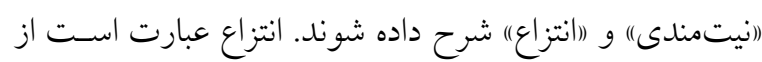
ساختن يكى سرى مفاهيم كلى ذهنى كه اين مفاهيم عينـاً مابـه

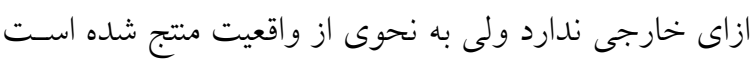

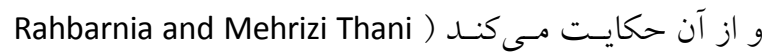
2008). در ارتباط با مفهوم (انيتمندى)" رلف معتقد اسـت كـه

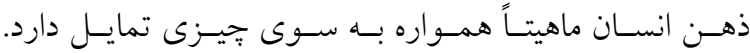

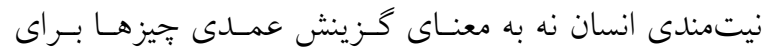
شناخت، بلكه به معناى حضور يا بودن در ميان ديخر انسانها

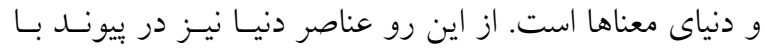

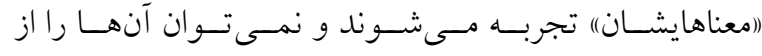

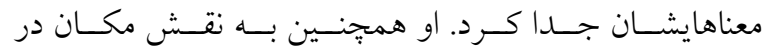
((نيتمندى) اشاره مى كنــــ از ديـــاه او، مكـانهـا، زمينـهــا يا بسزمينههايى (Context)

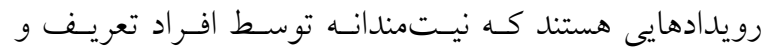

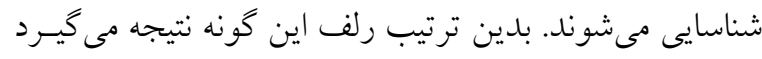

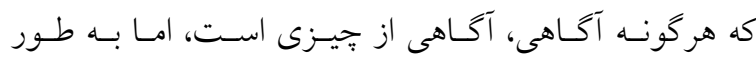

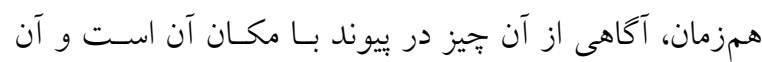

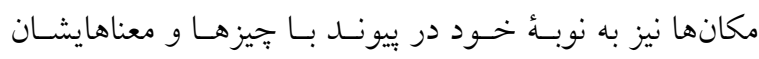

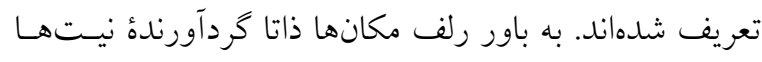
هستند. به باور رلف جوهر مكان در نيتمنـدى رلفى (Intentions)

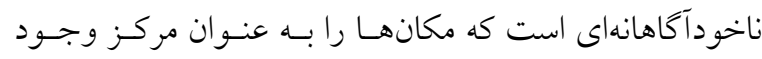

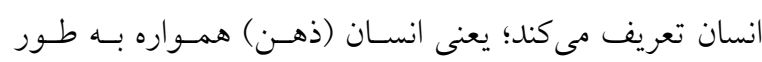

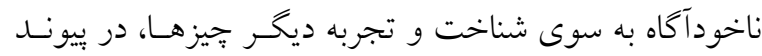


Gee and Burkhard ) طبـق گفتسههـاى گى و برخــارد

2010) معانى، ناشى از روابط خاص بين ناظر و محيط اسـت. بوستانهاى شهرى طيف وسـيعى از معـانى را بـراى كـاربران

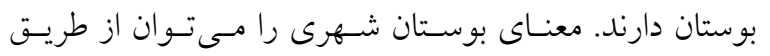
معنايى كه توسط كاربران تفسير مىشود درك كـرد. همـانطور كه استوارت (Stewart 2008) اظهار مى كند، (معانى مكـانهـا

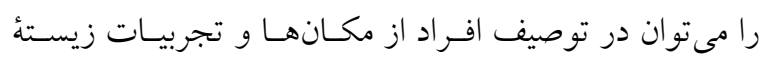
آنها در آن مكانها يافت)، بنابراين براى كشـف معسانى، لازم

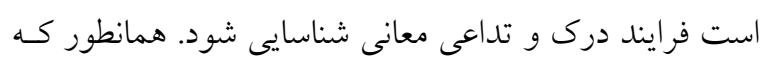
در مطالب بيشين نيز بيان شـد، ادراك در يسنج مرحلـه انجـام مىشود: تحريك، سـازماندهى، تفسـير - ارزيـابى، حافظهه و تداعى. شكل r فرايند ادراك در بوستانهاى شهرى را نشـان

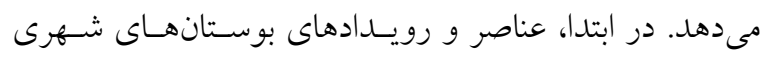

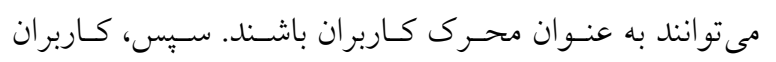

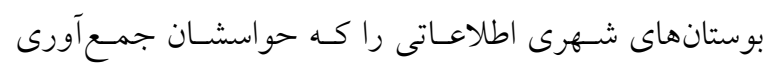

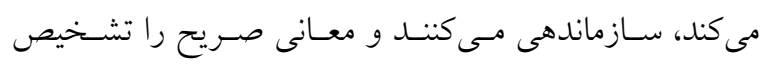

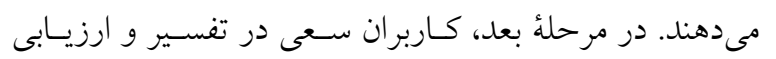

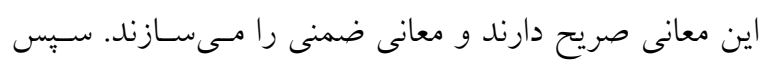
اين معانى ضمنى در حافظه قرار مى گيرنــــ و افـــاد اطلاعـات

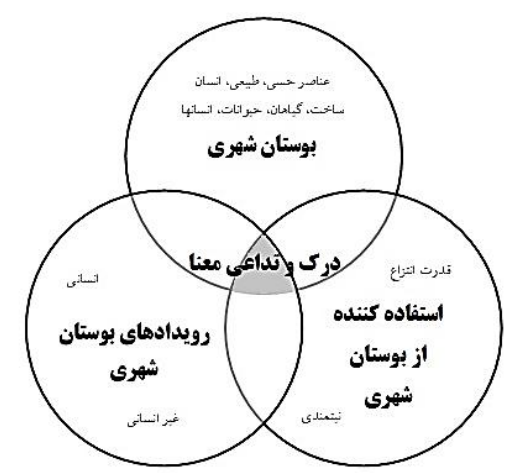

تصوير ا: ارتباط درك و تداعى معنا و رويدادها در بوستان شهرى Fig. 1: Events pattern in urban parks

آن را مكانى راحت (به جهت سـايهانـدازى) بــراى خوابيـدن بداند. نمونهُ ديخر مىتواند كسى باشد كه يك سبد كل زيبا را در يك بوستان مشاهده مى كند. او ممكن است به دليـل درى بـ بـ

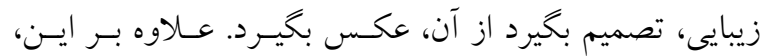
رويدادهاى غيرانسانى نيز مى تواند برخى از معانى و تداعىهـا

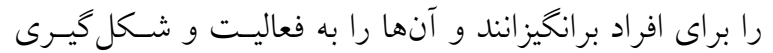
رويداد انسانى وادار و يا تشويق كنند. به عنوان مثال، يـك زن و شوهر ممكـن اسـت در يـك روز بـارانى در يـك بوستان

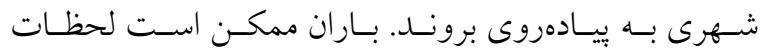

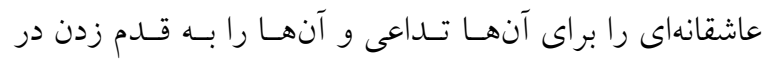

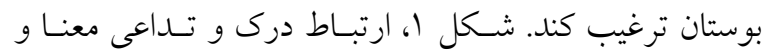
رويدادها را در بوستان شهرى نشان مىدهد.

\section{فرايند ادراك در بوستان هاى شهرى}

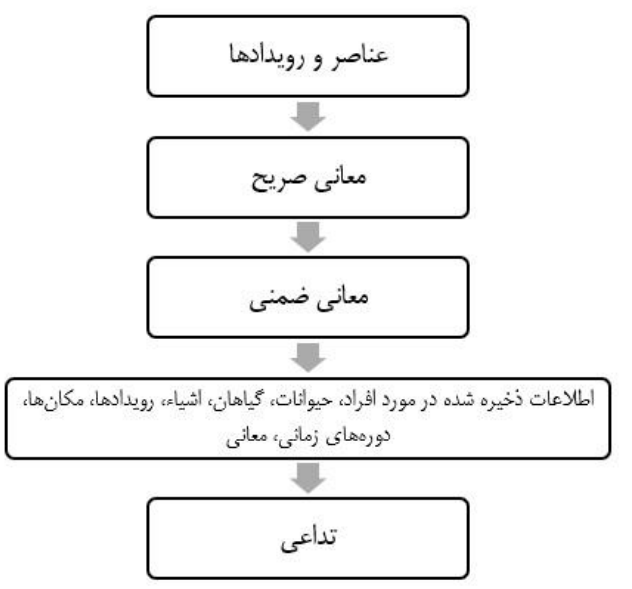

تصوير ז: فرايند ادراك در بوستان هاى شهرى

Fig. 2: The Process of Perception in Urban Parks

تنظيم از نغارندًان بر اساس: DeVito 2012

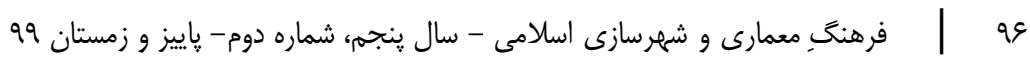


تبيين الخوى برناملريزى فرهنگى بوستانهاى شهرى

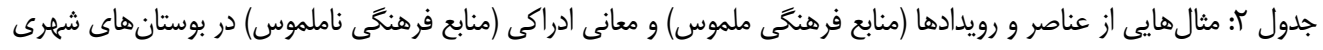

Table 2: Some examples of elements and events (tangible cultural resources) and meanings and associations (intangible cultural resources) in urban parks

\begin{tabular}{|c|c|c|}
\hline معناى ادراكى (منبع فرهنكى ناملموس) & عنصر يا رويداد (منبع فرهنكى ملموس) & ئزوهشخر \\
\hline خوشحالى & نشستن روى نيمكت بالاى يك تِه و نغاه كردن به افق & \multirow{5}{*}{$\begin{array}{l}\text { Burgess et al } \\
1988\end{array}$} \\
\hline 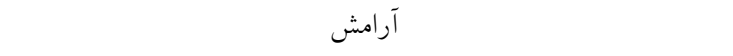 & يِيادهروى به سمت پايين بوتها و تماشاى سنجابها & \\
\hline 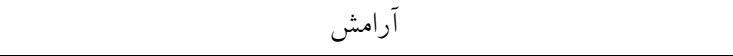 & نشستن در سكوت روى نيمكت و مراقبه & \\
\hline 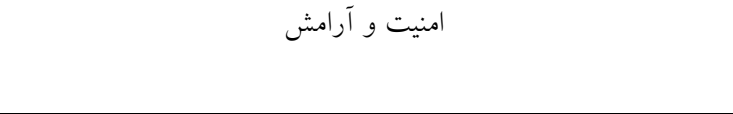 & بازى كودكان و تخليه انرزى در كنار مادرانشان در & \\
\hline دوستى و معاشرتيذيرى & يافتن دوستان جديد براى كودكان و بازى با آنها & \\
\hline احساس آرامش، راحتى و آسايش & نيمكت & Manzo 2005 \\
\hline 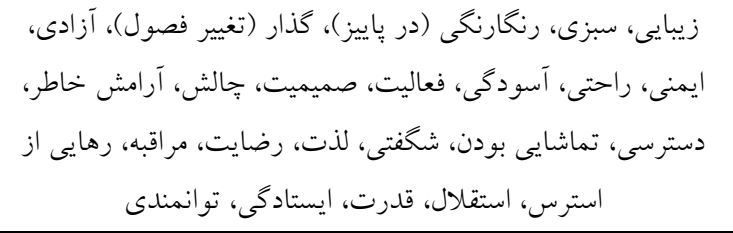 & درختان، گياهان، افراد، راه، منظره طبيعى & Krenichyn 2006 \\
\hline غوطهورى، بههم ييوستكى، آزادى، انزوا، آرامش & كل بوستان & \multirow{8}{*}{$\begin{array}{l}\text { Wynveen et al } \\
2010\end{array}$} \\
\hline شخفت انخيز، افسانهاى و جشمخير & رنخ و شفافيت آب & \\
\hline آرامش و راحتى & آب & \\
\hline منحصر به فرد بودن، انزوا، تنهايى & محدوده جزيرهاى نخل خرما & \\
\hline زيبايى، ايمنى و دسترسى & صخره & \\
\hline 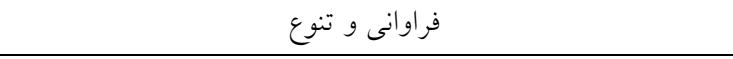 & 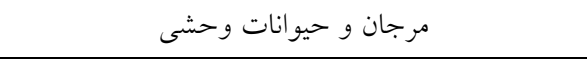 & \\
\hline كنجكاوى و اكتشاف & قايقرانى و غو اصى & \\
\hline زيبايى & منظره دريا و مناظر باز & \\
\hline ايمنى، آسودگى و باهم بودن & بوستان & \multirow[t]{3}{*}{ Peters 2010} \\
\hline ناراحتى و نبود آرامش & خيره نخاه كردن نوجو انان مر اكشى و متلك كفتن به & \\
\hline بى حرمتى & توهين بجهه ها به مهاجران & \\
\hline 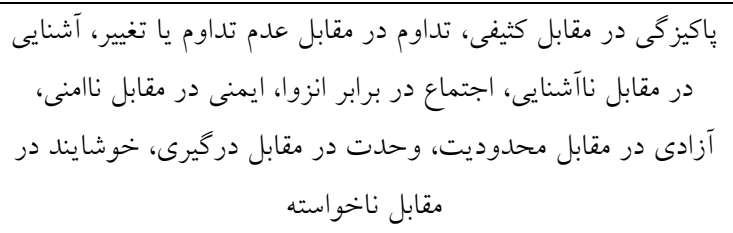 & بوستان & Main 2013 \\
\hline 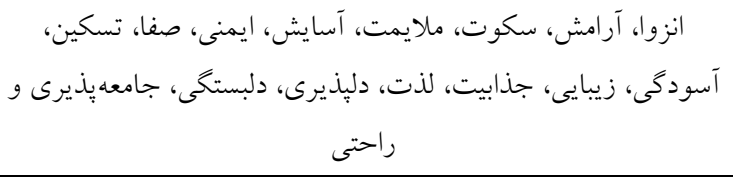 & بوستان & $\begin{array}{l}\text { Campbell et al } \\
2016\end{array}$ \\
\hline فراغت، باكى، طبيعى بودن، آزادى، آرامش، راحتى، سكوت، و زيبايى & بوستان & $\begin{array}{l}\text { Loukil et al } \\
2010\end{array}$ \\
\hline آزادى، شانس، ماجراجويى، خوشبختى، يخانكى با خود و يكانكى & بوستان & Chiesura 2004 \\
\hline جذابيت، دور بودن، وسعت و سازكارى & بوستان & $\begin{array}{l}\text { Rennit, Maikov } \\
2015\end{array}$ \\
\hline
\end{tabular}


كرفتهاند، تفسير مى كنند. بنـابراين، واقعيـت اجتمـاعى جيـزى

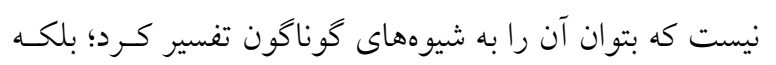
واقعيت اجتماعى، همان تفسيرهاى افراد است (Ibid).

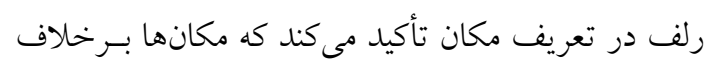

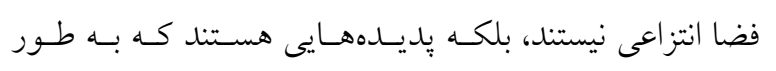
مستقيم از جهان تجربه مىشوند؛ بنـابراين سرشـار از معـانى، جيزهاى واقعى و فعاليتهاى جارى در آن هسـتند. مكـانهـا منابع مهم شناسايى اشخاص و اجتماعها محسوب مى شيوند و و

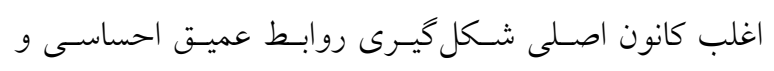
فيزيكى ميان انسـانهـا را شـكل مسىدهنــ (Pakzad 2018). بنابراين تعريف اين يزوهش از مكان عبارت است از: (امكـان، فضايى فيزيكى است كه دربر گيرندهُ معانى، تداعىها، عناصـر

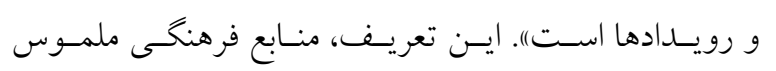

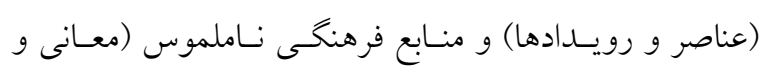
تداعىها) را شامل مىشود. مكانى كه در اين يزوهش مورد نظر بوده، بوستان شهرى است. كلمه (بوستان) مركب از (بو)) (رايحه) و (اسـتان) (ادات مكان) به معناى جايى است كه كلهاى خوشبو در آن، بسيسار باشد (Dehkhoda 2011)؛ اما در بعضى مطالعات شهرى و از سوى نهادهاى عمومى و دولتى، وازةه (بوستان)، بـه جـاى وازٔه

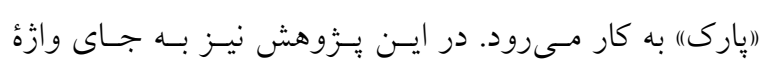

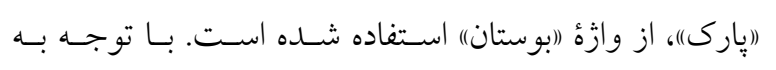

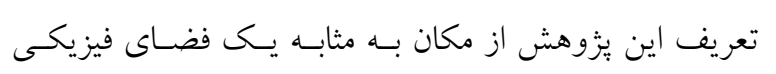

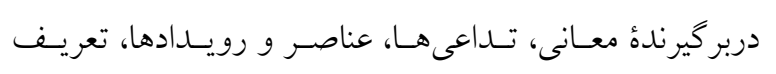
بوستان شهرى در اين يزوهش عبارت است از: (فضـاى سـبز

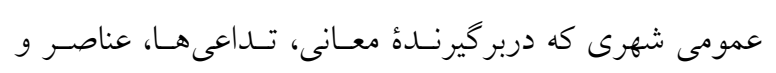

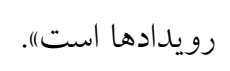

\section{ع. يافتهاها و بحث}

بوستانهاى شهرى مىتوانند براى گروههاى مختلف از مـردم، وحته

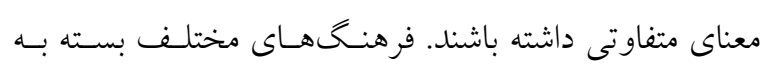

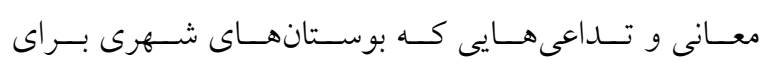

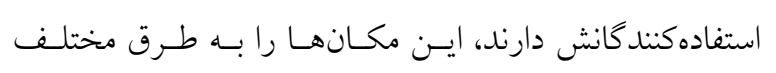
معنادار مى كنند. عناصر انسانساخت، عناصر طبيعى، گياهـان،
ذخيره شده در مورد افراد، حيوانات، گياهان، اشياء، رويدادها، مكانها، دورههاى زمانى، معانى و غيــره را بازيـابى مسى كنتـد.

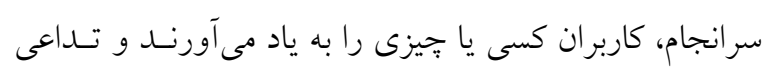
صورت مى گيرد. تعدادى از يزوهشخر ان به درى معانى توسط كـاريران در

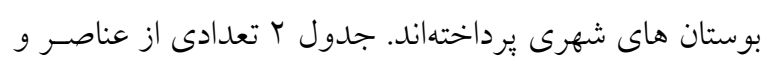
رويدادهاى موجود در بوسـتانهـاى شهرى (منـابع فرهنخـى بردي ملمـوس) و تـأثيرى را كـه در ايجـاد معـانى ادراكى (منــابع فرهنكى ناملموس) دارند از ديـدكاه تعـدادى از يزوهشـحران نشان مىدهد.

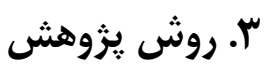

همانطور كه كيلاردى (Ghilardi 2001) يكى از فولى فعالان حرفــ

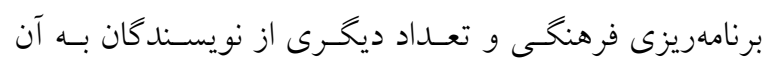
اشاره كردهاند، برنامهريزى فرهنكى يكى رويكرد مكان محسور

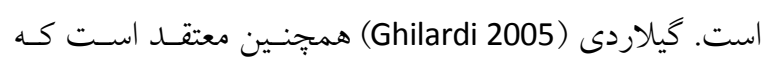

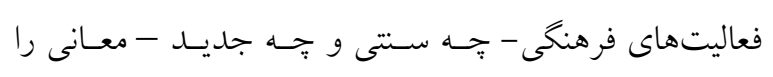

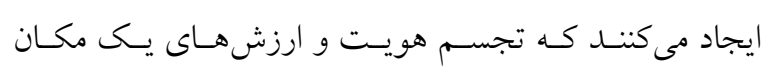

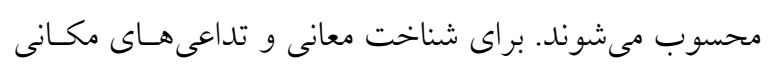

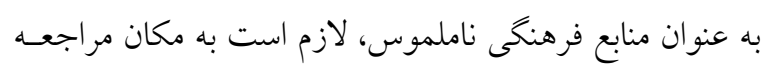

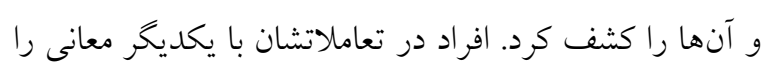

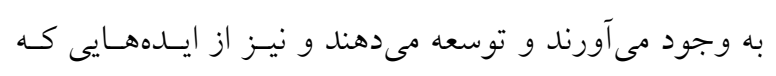

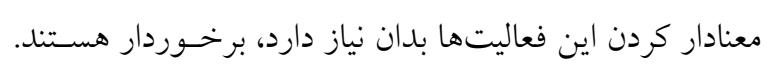
همانطور كه بليكى مىنويسد: جهان اجتمـاعى يسيش از آغـاز كار يزوهشخر علوم اجتماعى، همواره مورد تفسير (سازند آنان آن) قرارگرفتـه اسـت (Blaikie 2017)، بــراى درك و تفسيـير

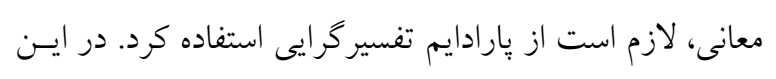

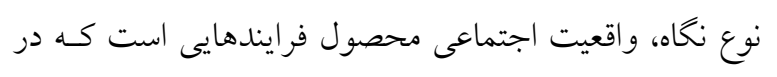

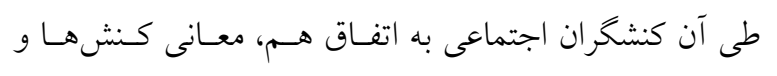

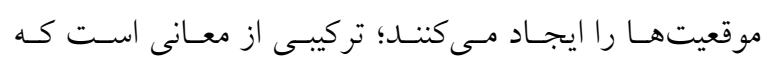

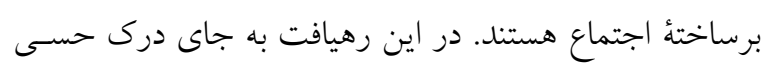

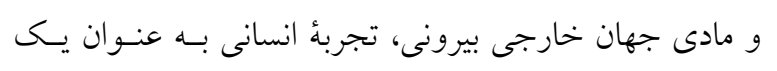

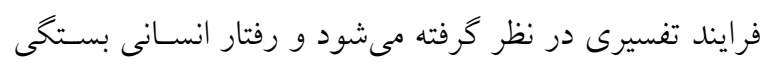

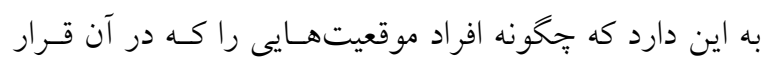


جدول ץ : عناصر بوستانهاى شهرى

Table 3: Urban parks elements

\begin{tabular}{|c|c|}
\hline ت ت تعدادى از مثالها & عناصر \\
\hline 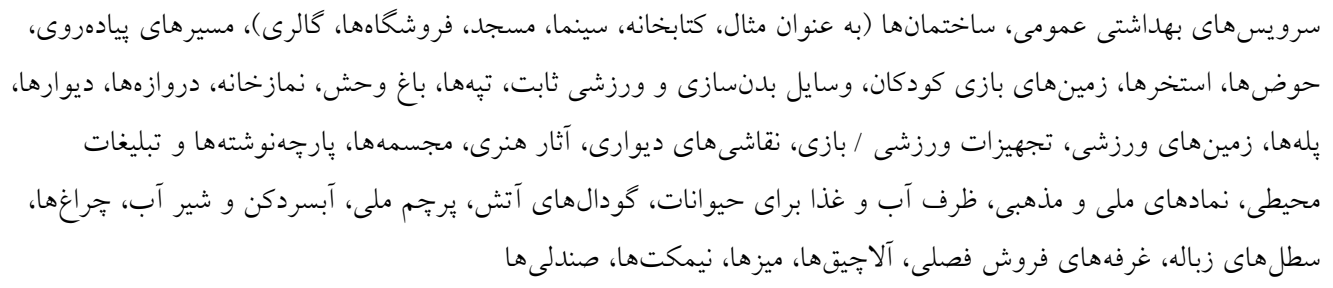 & 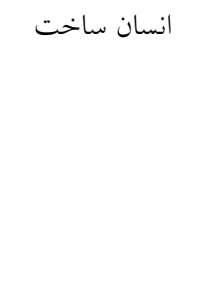 \\
\hline خاك، آب & طبيعى \\
\hline رنخ، بو، صدا، مزه، جنس & 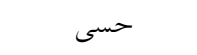 \\
\hline بوتهها، جمنزار، درختان سايهدار، درختان ميوه، كياهان خوراكى & كياهان و درختان \\
\hline كربهها، سگها، يرندگًان، جوندگان، خزندگان، حشرات & 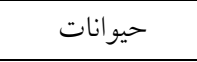 \\
\hline 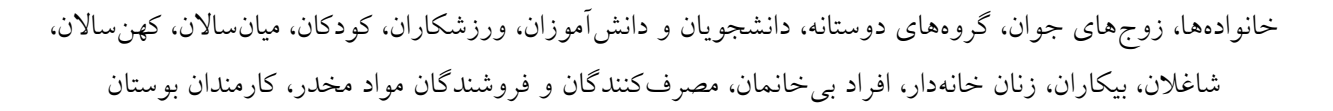 & 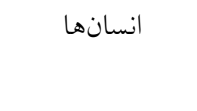 \\
\hline
\end{tabular}

رويدادهاى انسانى مربوط به فعاليتها و كارهايى هستند كه

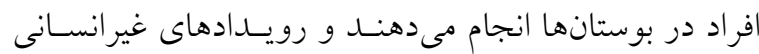
مربوط به شرايط آبوهوايى، فعاليتهاى حيوانات و مراحل رشد كياهان در بوستانها هستند. جــدول ع نمونسهــايى از اين دو نوع رويداد در بوستانهاى شهرى را نشان مىدهد. برنامهريزى فرهنكى يكى رويكرد مكان محـور اسـت و و بر منابع فرهنكى يك مكان متمركز اسـت (Ghilardi 2001). اما برنامهريزى فرهنكى بوستانهـاى شـهرى شـامل مراحـل مختلفى است كه لازم است به ترتيب انجام شوند تـا نتيجـهـ

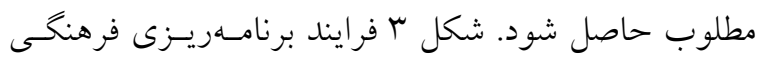
بوستانهاى شهرى را نشان مىدهد. كام اول در برنامهريزى فرهنگى بوستانهاى شهـرى، انتخـاب

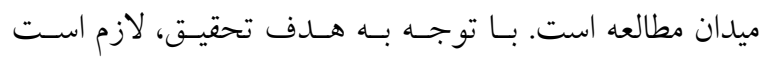
بوسـتانى انتخـاب شـود كـهـ تعـدد و تنـوع كـافى در زمينـهُ
حيوانات و انسانها نقش اصلى و تعيين كننده در بوستانهـاى شهرى براى درى و تداعى معانى برعهلده دارند. بنابراين، ايـن عناصر به همراه رويدادهاى انسانى و غير انسانى مى تو اننـــ بـهـ عنوان عناصر ملموس در منابع فرهنكى بوسـتانهـاى شـهرى

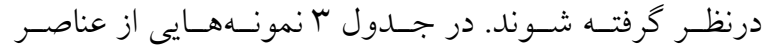
بوستانهاى شهرى قيد شده است. به كَتهُ الكساندر (Alexander 2017)، فهرست عناصـر موجود در يكى بوستان شهرى، نحوهُ زندگى افراد را در آنجا تعيين مى كند و هر يـك از ايـن عناصـر الخــى خاصسى از

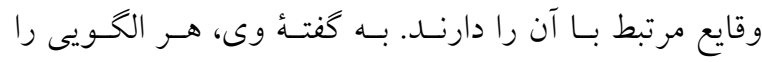
مىتوان با ويزگكى فضايى آن بوستان شهرى تعريـف كـرد و الكوى كل وقـايع انسـانى در يـك بوسـتان شهـرى، توسـط

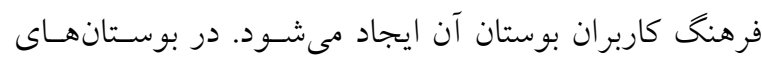
شهرى دو نــوع رويسـاد وجــود دارد: انسـانى و غيرانسـانى.

جدول ع. رويدادهاى بوستانهاى شهرى

Table 4. Urban parks events

\begin{tabular}{|c|c|}
\hline مثالها & رويدادها \\
\hline 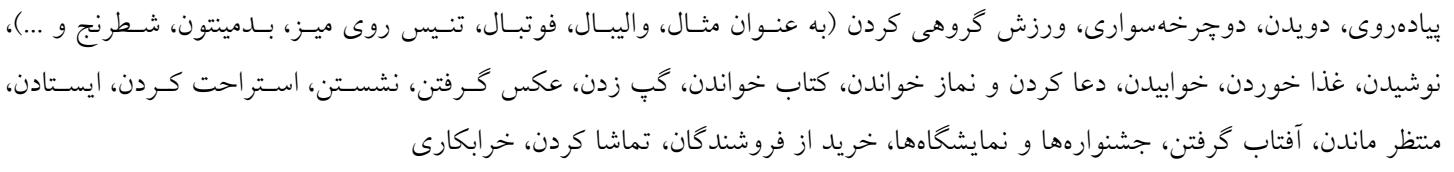 & انسانى \\
\hline 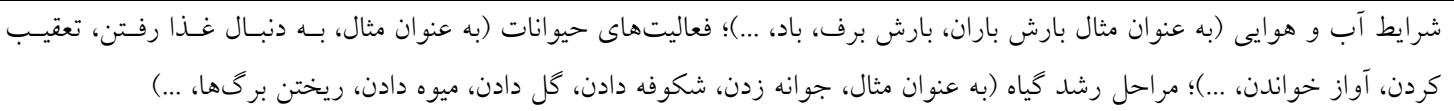 & غير انسانى \\
\hline
\end{tabular}




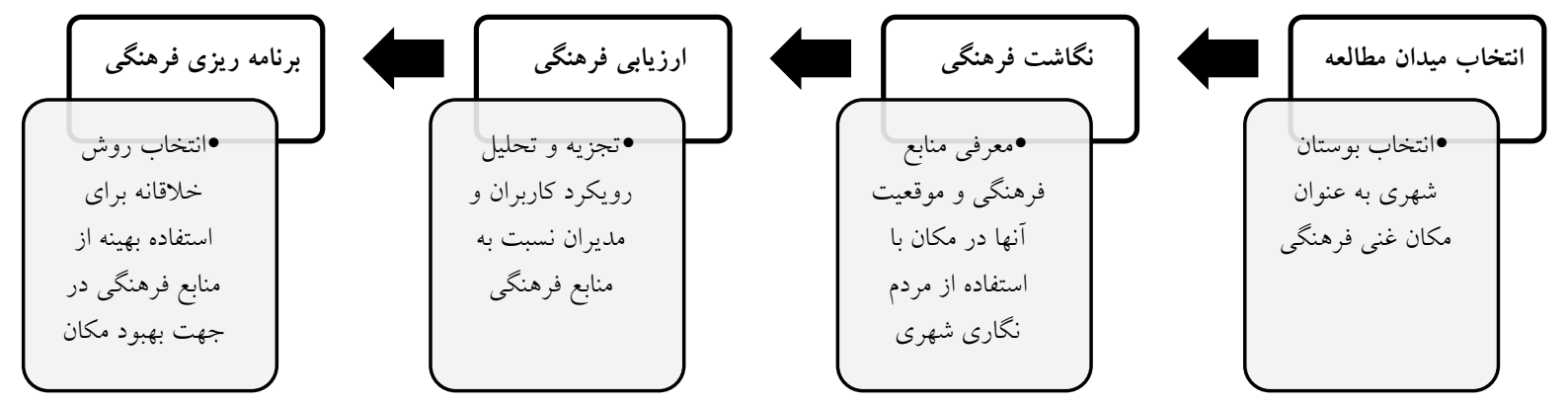

تصوير "ا: فرايند برنامهريزى فرهنگى بوستانهاى شهرى

Fig. 3: Cultural planning process of urban parks

آنجه در اين مرحله صـورت مسى گيسرد، شناسـايى منـابع

فرهنكى موجود بوستان شهرى مورد مطالعه است. ايسن منسابع فرهنخى شامل منابع فرهنكى ملموس (عناصر و رويــادها) و

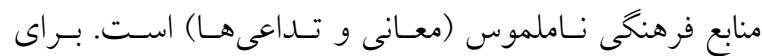
شناسايى منابع فرهنكى لازم است از روش مردمنگارى شهرى استفاده شود. در بسيارى از يزوهش هاى بيشين، از مردمنگارى براى شناسايى عناصر و رويدادهاى بوستانهاى شهرى استفاده

شده است (ر.ى. Ejlali and Anjam Shoa 2012 ). كام سوم در برنامهريزى فرهنخـى بوسـتانهـاى شـهرى،

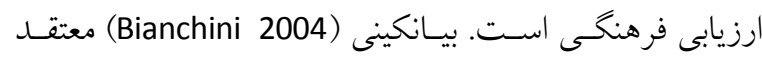

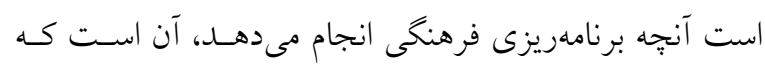

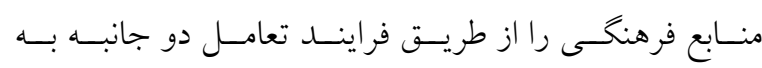
سياست گذارى مرتبط مى كند. كيلاردى (Ghilardi 2001) نيـز فئز

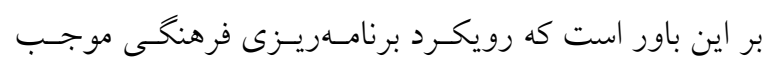

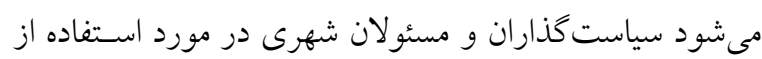
منابع فرهنكى محلى براى طيف وسيعى از سياست گذارى بــه صورت راهبردى فكر كنند. در اين مرحله لازم است رابطهاى دو جانبه بين منابع فرهنكى بوسـتان شهرى مـورد مطالعسه و

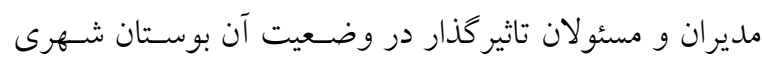

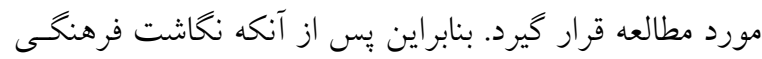
انجام شد؛ يعنى منـابع فرهنخـى و موقعيـت مكـانى آنهـا در بوستان شهرى شناسايى شــند، لازم بــود رويكـــد مـــيران و كاربران اين بوستان نسبت به اين منابع فرهنكى مشخص شود تا ديدكاههاى آنان و ميزان مطابقت اين ديدكاهها بـا يكـديخر تعيين شود. در اين راسـتا، عـلاوه بــر مصـاحبه بــا مــديران و

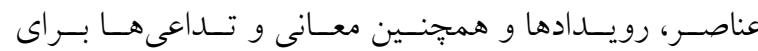
استفادهكند كان داشتهباشد. كام دوم، نگاشت فرهنخى اسـت. نخاشت فرهنكى، شناسـايى و تجزيسه و تحليـل جـامع منــابع فرهنكى يك جامعه است كه از طريق يـك فراينــ مشـاركتى كسترده انجام مى شود. نخاشت فرهنكى، مرحلة اوليه و مهم در برنامسهريـزى فرهنخـى اسـت (2010 Legacies Now 2010).

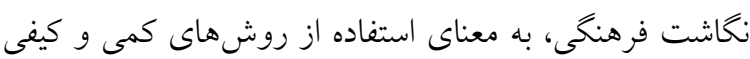

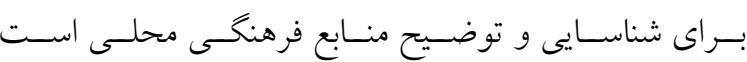

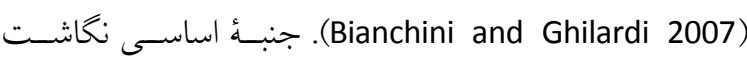
فرهنكى اين است كـه منـابع را بـهـ عنـوان (دارايسى) در نظـر

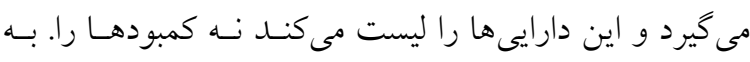
عبارت ديخر، بر آنجه در يك منطقه وجود دارد تمركز مى كند، نه بر آنجهه وجود ندارد يـا مشـكل سـاز اسـت. اتخـاذ جنسين

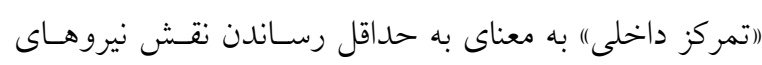

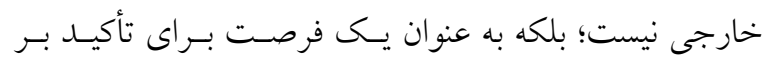

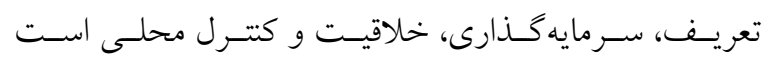
(Ghilardi 2010). نگاشت فرهنخى، به معناى شناسايى، تحت كترل درآوردن و سبس بهرهبردارى از قابليتها و از امكانات

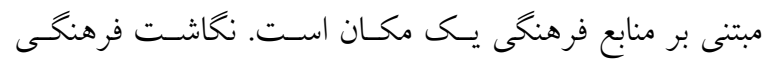
روشى است كه مىتواند براى تعريف فعاليتهـاى فرهنخى، ظرفيتها و نيازهاى يك جامعه مورد استفاده قرار كيرد. جنين

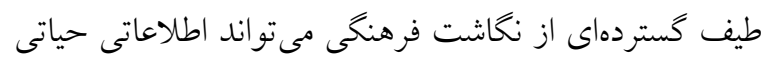

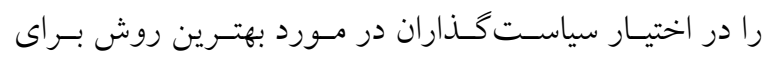
ياسخخويى مؤثرتر به نيازهاى محلى قرار دهد و در عين حال فرصتها را به حداكثر برساند (Ghilardi 2005). 
جنسيت، قوميت، زبان و تنوع منابع فرهنكى، لازم است انسواع

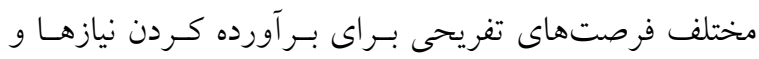

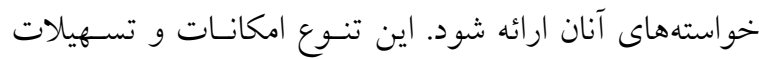

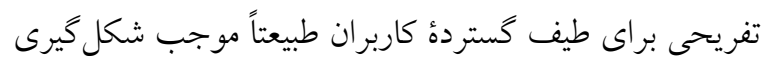

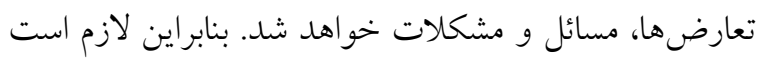

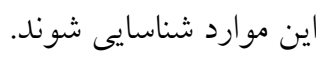

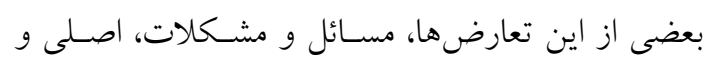

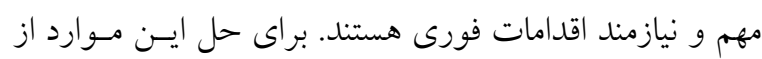

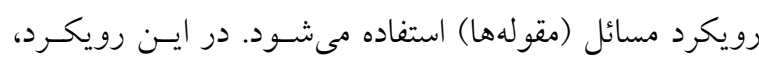

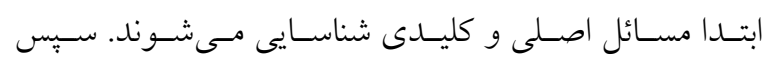

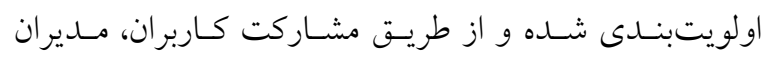

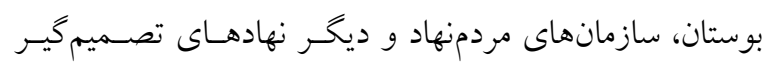

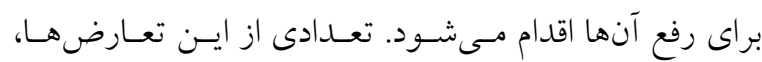

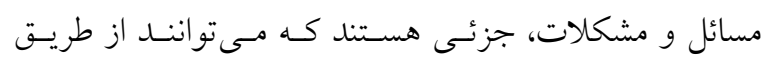

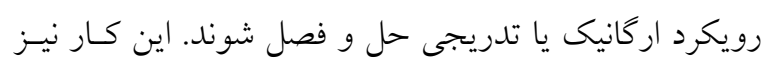

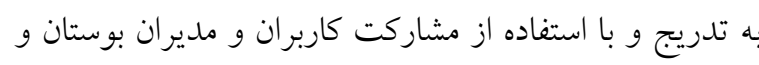

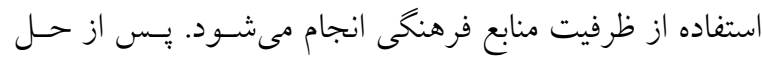

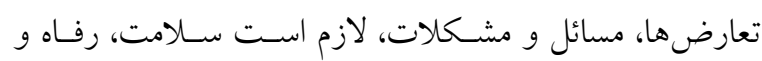

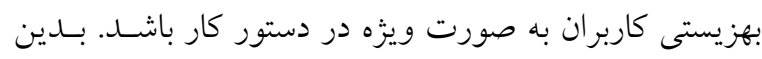

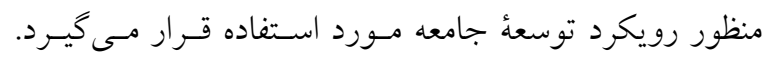

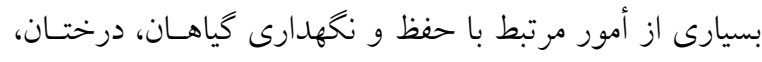

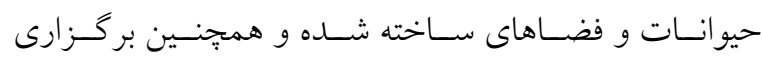

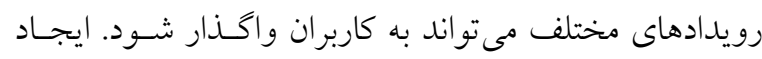

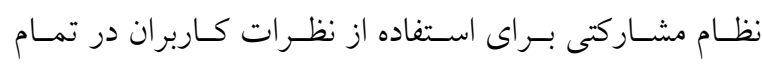

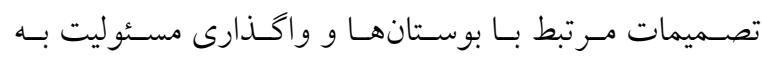

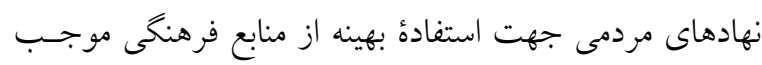

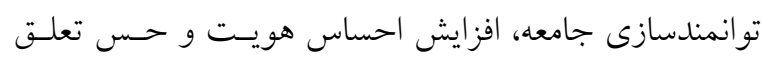

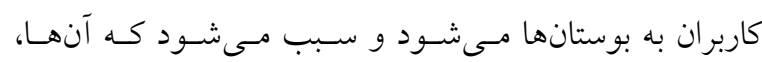

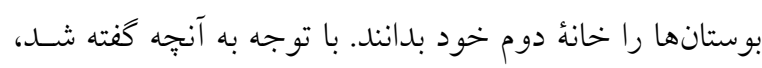

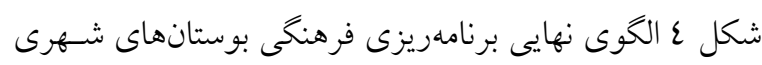
را نشان مىدهد.
سياست كذاران و نهادهاى تأثير حـذار در وضـعيت آن بوسـتان شهرى، سياستها و رويكرد سازمانها و نهادهـاى متـولى آن بوستان شهرى نيز مورد ارزيابى قرار كرفت. سئ.

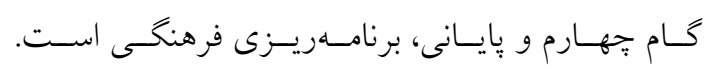
برنامهريزى فرهنكى، ترغيب سياست كذاران و مسئولان شهرى

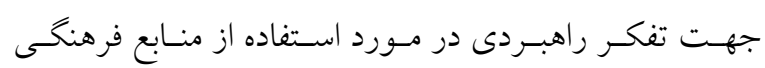

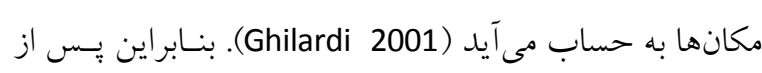

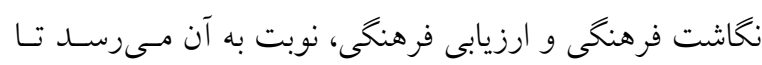

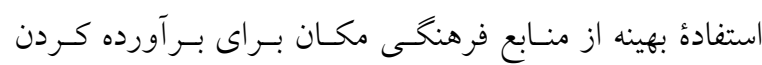

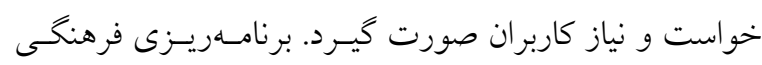

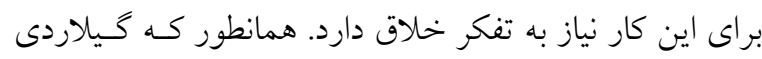

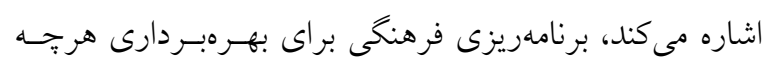

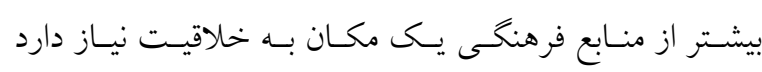

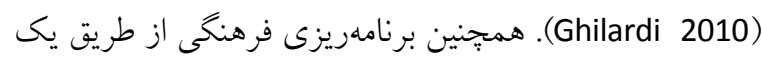

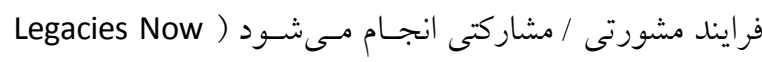

(2010

براى شروع برنامهريزى فرهنگى بوستانهاى شهرى، ابتدا بوستان شهرى مورد نظر انتخاب مى شود. لازم است اطمينـان

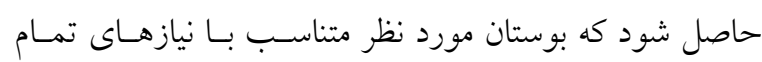

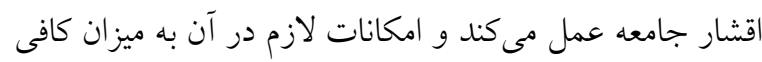

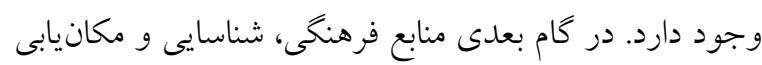

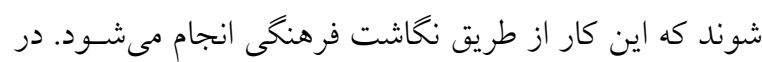

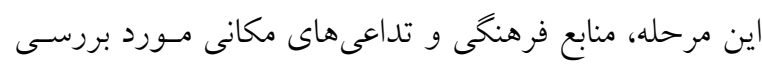

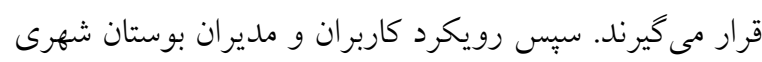

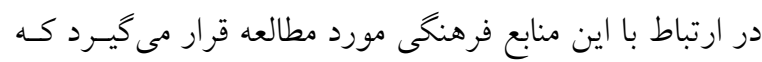

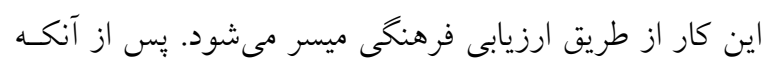

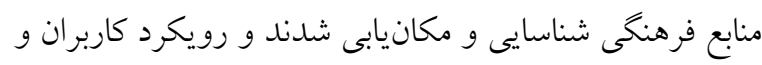

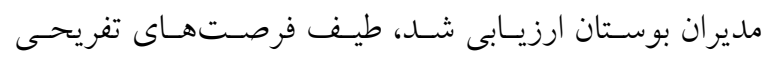

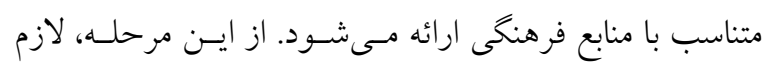

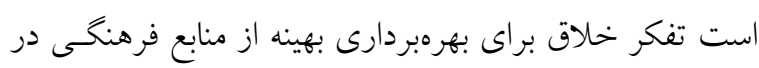

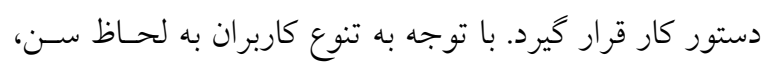




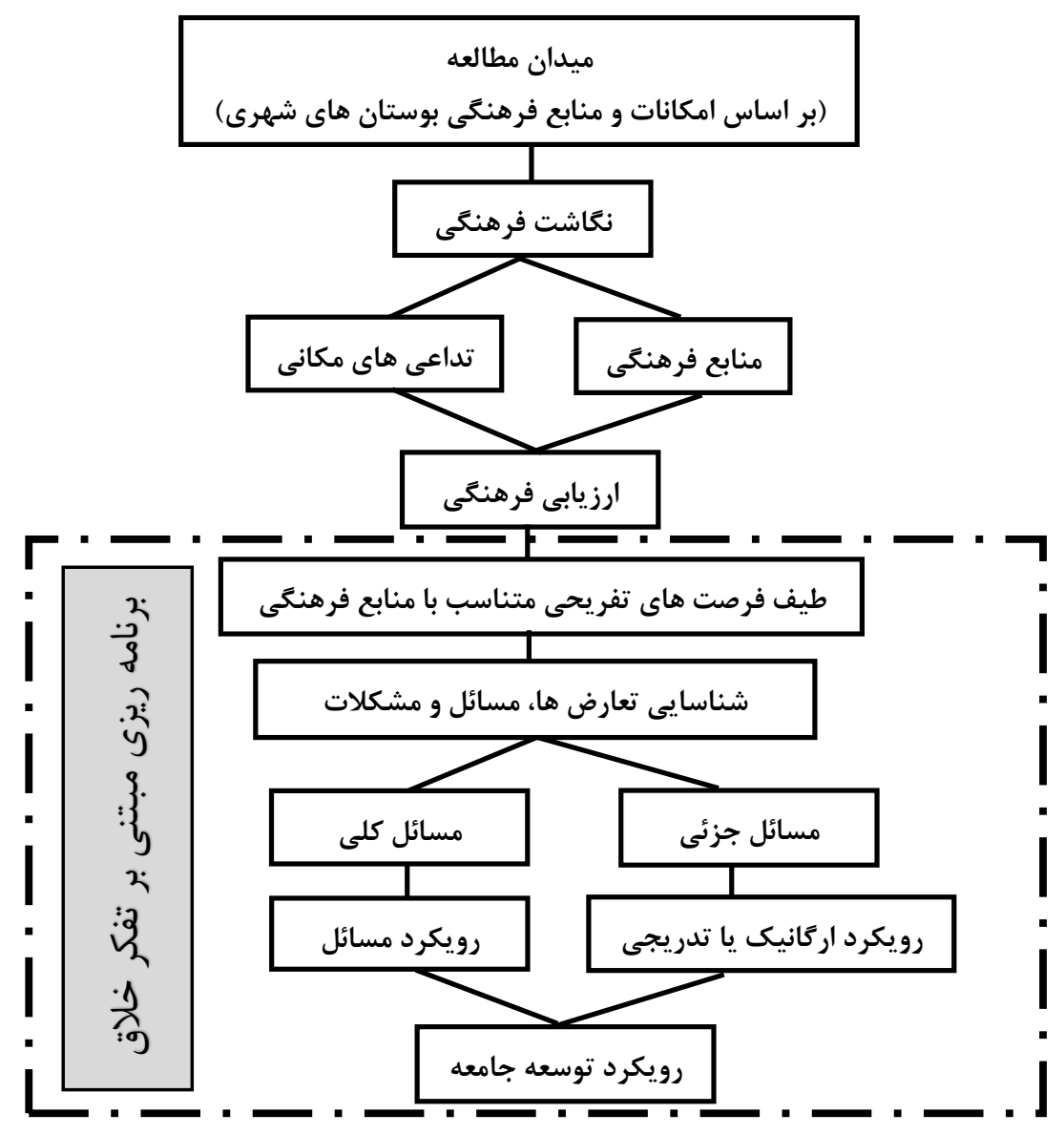

تصوير f: الكوى نهايى برناملريزى فرهنكى بوستانهاى شهرى

Fig. 4: The final model of cultural planning of urban parks

\section{نتيجلكيرى}

رويداد وجود دارد: انسانى و غير انسـانى. رويــادهاى انسـانى فعاليتهايى هستند كه افـراد در بوسـتانهـاى شـهرى انجـام مى توانند منجر به شكل گيرى معـانى و تــاعىهـا بــه عنـوان

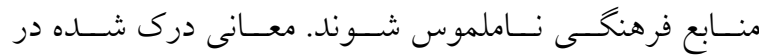
بوستانهاى شهرى مىتواندل برخى از افراد، حيوانات، گياهان،

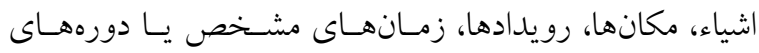
زمانى خاص يا حتى معـانى ديخـــ را بــراى كـاربران بوسـتان تداعى كنند. بنابراين، منابع ملموس و ناملموس بـهـ عنـوان دو

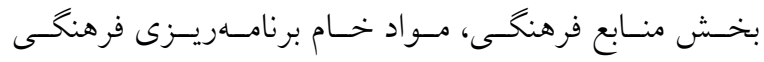
بوستانهاى شهرى است.

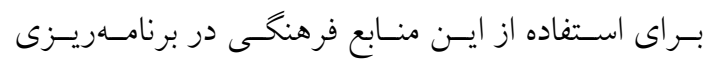
فرهنكى بوستانهاى شهرى لازم است مراحلى انجام شـود تـا
مطالعهُ حاضر در يى يافتن الكويى براى برنامهريزى فرهنخىى بوستانهاى شهرى بوده است. در بوستانهاى شهرى دو نـوع بـ بـ

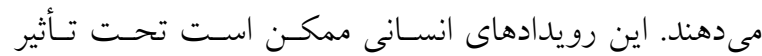
عناصر انسانساخت، عناصر طبيعى، حسى، گياهان، حيوانـات و انسانها باشند. اين عناصر يـاد شــه، از مؤلفـهــاى منـابع

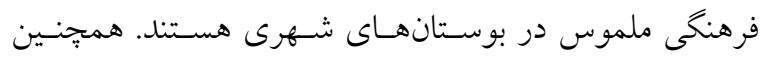

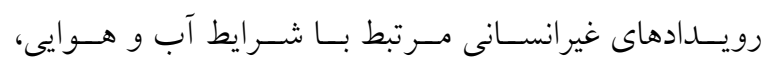

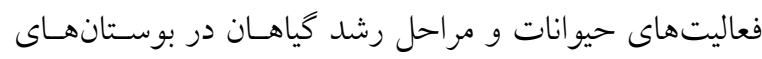

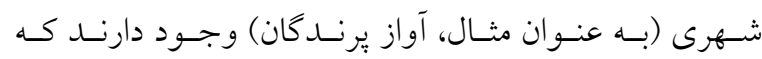
مىتوانند در شكل گيرى رويدادهاى انسانى نقش داشته باشند.

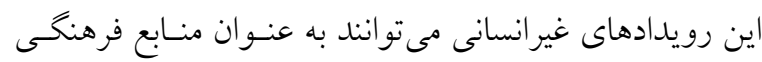

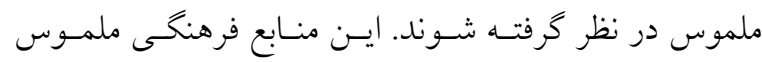


مكان براى برآورده كردن خواسـت و نيـاز كساربران صـورت

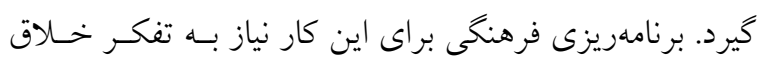

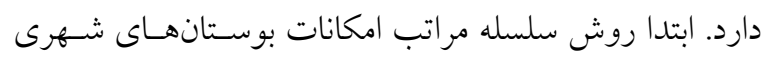

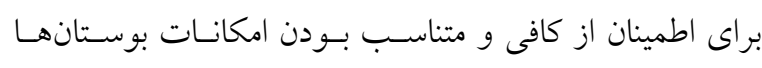

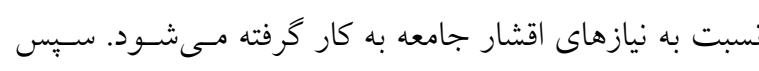

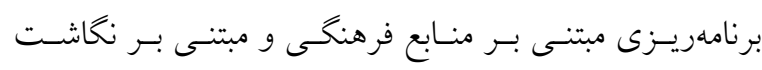

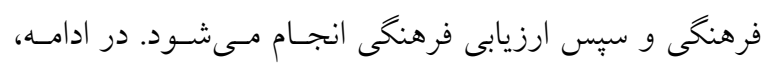

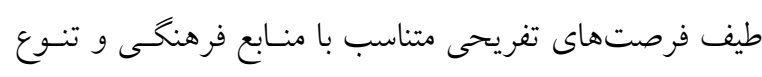

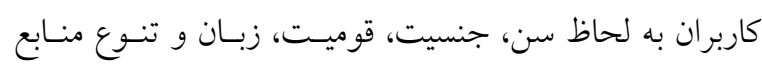

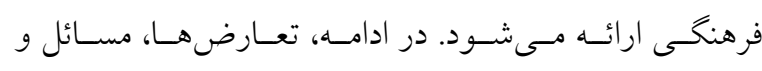

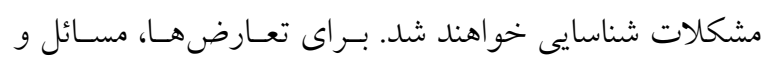

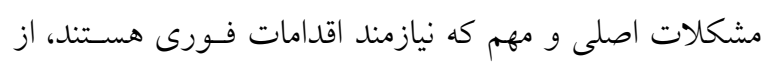

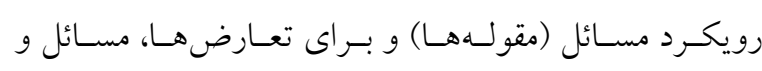

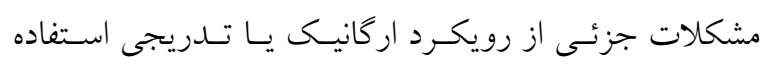

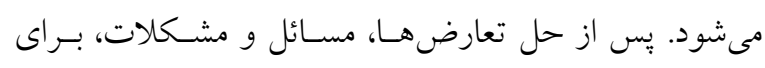

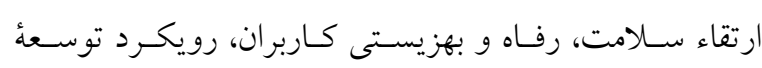
جامعه مورد استفاده قرار مى گيرد كه مىتواند با استفادة بهينـه.

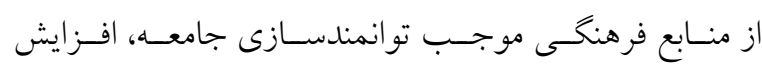
احساس هويت و حس تعلق كاربران به بوستانها شود.
نتيجه مطلوب حاصل شود. كَام اول انتخـاب ميـدان مطالعهـ

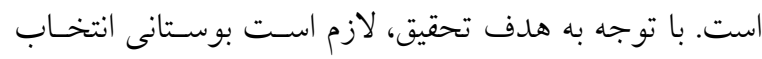

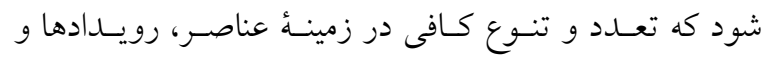

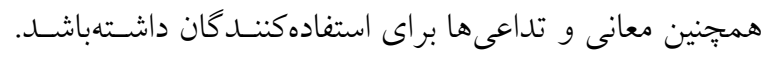

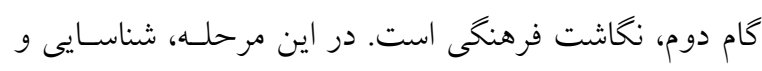

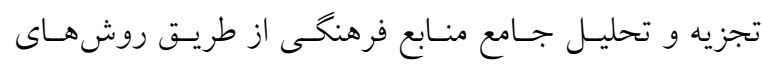

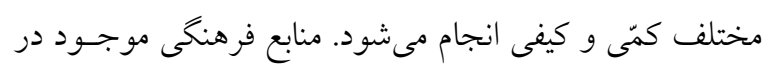

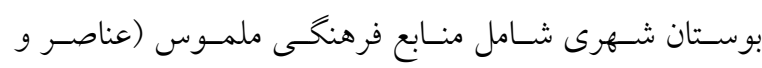

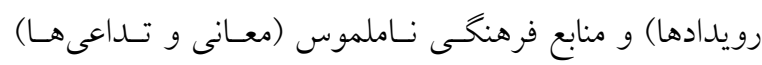

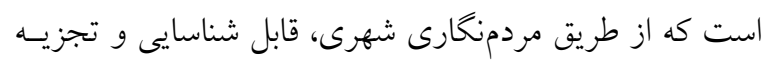

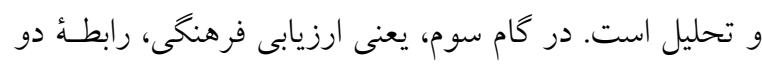

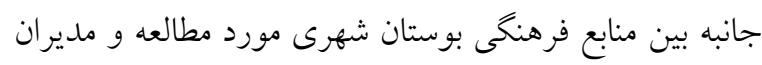

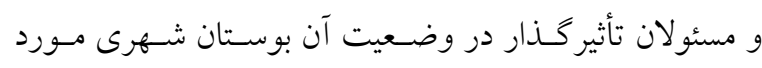

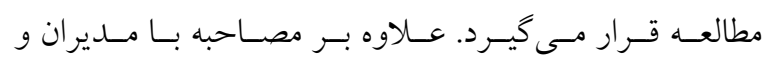

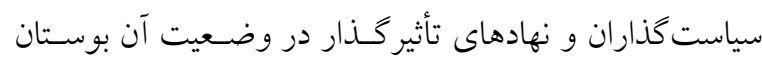

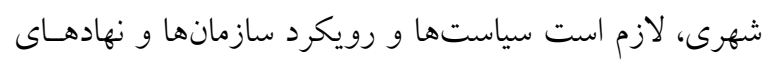
متولى آن بوستان شهرى نيز مورد ارزيابى قرار كيرد.

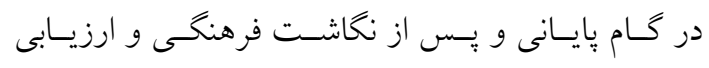

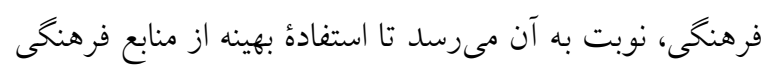

\section{فهرست منابع}

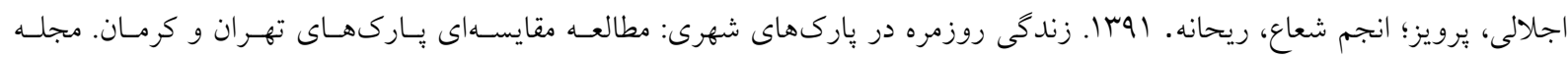

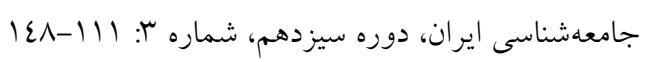

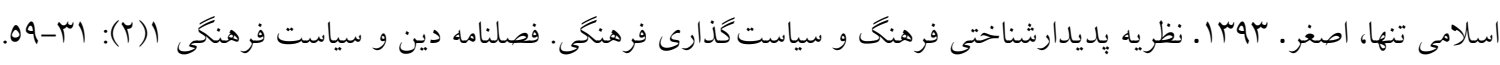
الكساندر، كريستوفر. بليكى، نورمن. سيد مسعود ماجدى. قم: يزوهشكاه حوزه و دانشخاه.

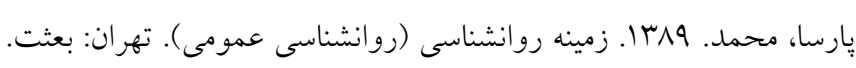

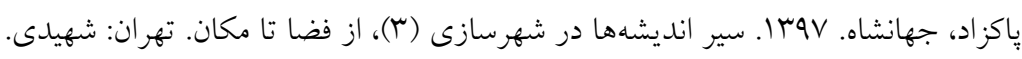

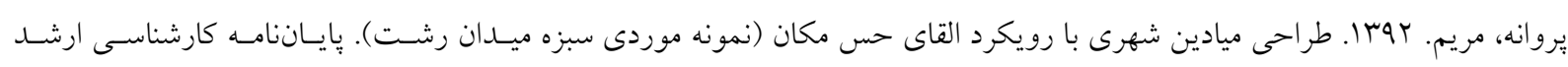
طراحى شهرى. دانشخاه كيلان.

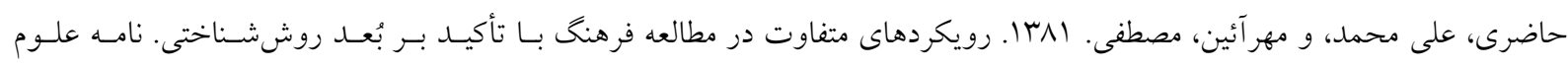

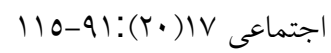

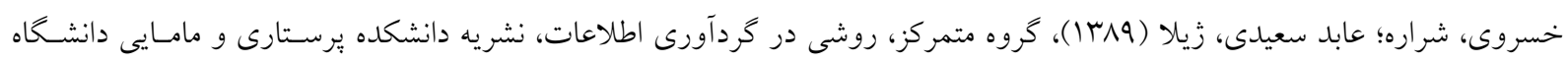

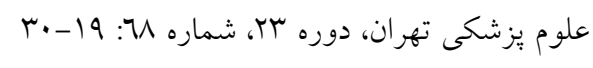




$$
\begin{aligned}
& \text { دارتيخ، آندره. } 97 \text { آا. بديدارشناسى جيست. ترجمه محمود نوالى. تهران: سمت. } \\
& \text { داورى اردكانى، رضا. IrNV } \\
& \text { دهخدا، على اكبر. •وب ا. لغتنامه دهخدا. تهران: دهخدا. }
\end{aligned}
$$

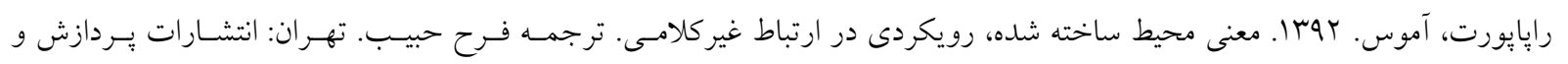

$$
\begin{aligned}
& \text { برنامهريزى شهرى. }
\end{aligned}
$$

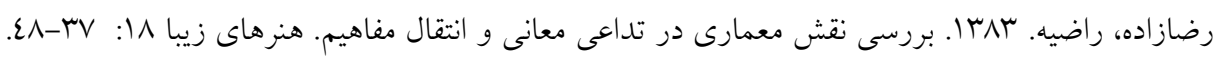

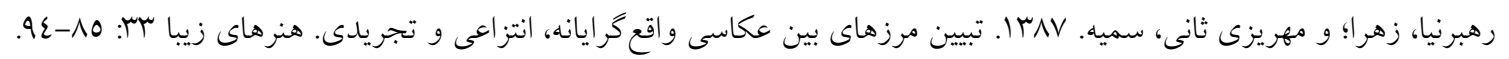

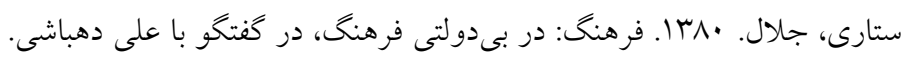

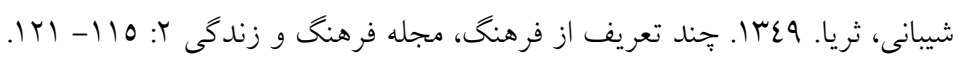

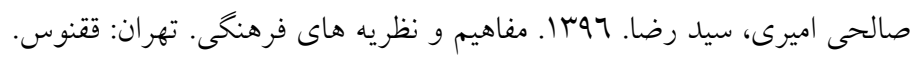

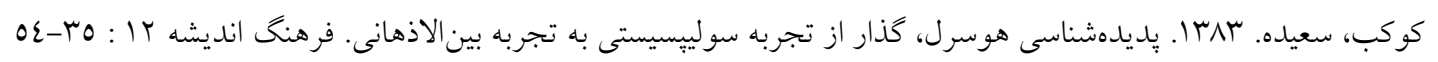

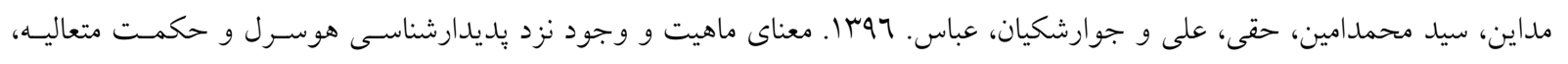

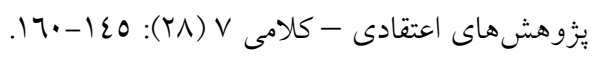

$$
\begin{aligned}
& \text { نوربرى شولتز، كريستيان. اوس|| معمارى: حضور، زبان، مكان. ترجمه عليرضا سيداحمديان. تهران: معمار نشر. }
\end{aligned}
$$

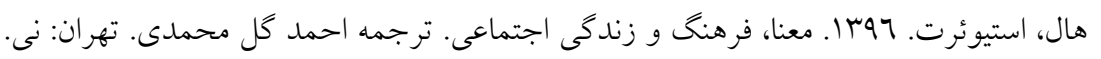

منابع انكَليسى

Alexander, C. 1979. The timeless way of building. Oxford University Press

Alexander, C. 2017.The timeless way of building. Translated by M. Qayyumi, Tehran: Rozaneh. [In Persian]

Arnold, M. 1869, Culture and anarchy, retrieved from http://public-library.uk/ebooks/25/79.pdf

Bianchini, F. 2004. A crisis in urban creativity? Reflections on the cultural impacts of globalisation, and on the potential of urban cultural policies. Paper presented at the international symposium The Age of the City: the Challenges for Creative Cites, Osaka, February $7^{\text {th }}-10^{\text {th }}$.

Bianchini, F.\& Ghilardi, L. 2007. Thinking culturally about place. Place Branding and Public Diplomacy 3(4)

Blaikie, N. 2017. Approaches to social enquiry. Translated by S.H.R. Hasani, M.T. Iman, S.M. Majedi. Qom: Research Institute of Hawzah and University. [In Persian]

Burgess, J., Harrison, C.M., \& Limb, M. 1988. People, parks and the urban green: A study of popular meanings and values for open spaces in the city. Urban Studies, 25, 455-473.

Campbell, L.K., Svendsen, E.S., Sonti, N.F., \& Johnson, M.L. 2016. A social assessment of urban parkland: Analyzing park use and meaning to inform management and resilience planning. Environmental Science \& Policy, 62, 34-44.

Chiesura, A. 2004. The role of urban parks for the sustainable city. Landscape and Urban Planning, 68, 129-138.

Dartigues, A. 2017. Quest-ce que la phenomenology. Translated by M. Navali. Tehran: Samt. [in Persian]

Davari Ardakani, R. 2008. Wisdom and time; conversations. Tehran: Sokhan. [In Persian]

Dehkhoda, A.A. 2011. Dehkhoda dictionary. Tehran: Dehkhoda. [In Persian]

DeVito, J.A. 2012. The interpersonal communication book. USA: Pearson.

Ejlali, P.; Anjam Shoa, R. 2012. Everyday life in urban parks: A comparative study of Tehran and Kerman parks. Iranian Journal of Sociology, 13 (3), 111-148 [In Persian]

Ellis, S.M. 2011. Intangible cultural resources: values are in the mind. in King, T. F. (ed.), A companion to cultural resource management, Blackwell.

Eslami Tanha, A. 2014. Phenomenological theory of culture and cultural policy, Quarterly Journal of Religion and Cultural Policy 1 (2), 31-59. [In Persian]

Fitzpatrick, A. 2009. Cultural planning as an instrument for locating Ontario provincial parks within the valuable landscape of a community, Master's thesis, the University of Waterloo

Gee, K., \& Burkhard, B. 2010. Cultural ecosystem services in the context of offshore wind farming: a case study from the west coast of Schleswig-Holstein. Ecol. Complexity, 7(3), 349-358.

Ghilardi, L. 2001. Cultural planning and cultural diversity, In T. Bennett (Ed.), Differing diversities: Cultural policy and cultural diversity (pp. 123-134), Council of Europe Publishing

Ghilardi, L. 2005. Culture at the centre: Cultural planning-A strategic approach to successful and sustainable community-

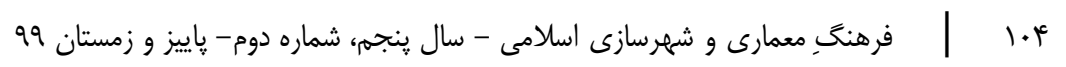


تبيين الكوى برنامهريزى فرهنگى بوستانهاى شهرى

based regeneration in Scotland, Noema research and Planning Ltd, London.

Ghilardi, L. 2010. Ambitious and resourceful cultural planners, Noema Research and Planning Ltd.

Hall, S. 2017. Representation: cultural representations and signifying practices. Translated by A. Golmohammadi. Tehran: Ney. [In Persian]

Harrison, K.D. 2007. When languages die: The extinction of the world's languages and the erosion of human knowledge. Oxford: Oxford University Press.

Hazeri, A.M., Mehraein, M. 2002. Different approaches to the study of culture with emphasis on the methodological dimension. Journal of Social Sciences 17(20). [In Persian]

King, T.F. 2011. A companion to cultural resource management. Blackwell.

Kokab, S. 2004. Husserl's phenomenology, the transition from the solipsistic experience to the intersubjective experience. Culture of Thought 12 [In Persian]

Krenichyn, K. 2006. The only place to go and be in the city: women talk about exercise, being outdoors, and the meanings of a large urban park. Health \& Place, 12, 631-643.

Loukil, B., Bouraoui, M., \& Donadieu, P. 2010. Urban parks in Tunisia: why and for whom?. Acta Hortic, 881, $759-765$.

Madayen, S.M.A., Haghi, A., Javareshkian, A. 2017. The Meaning of essence and existence in Husserl's phenomenology and transcendent wisdom, Belief-Theological Research 7 (28), 145-160. [In Persian]

Main, K. 2013. Planting roots in foreign soil? Immigrant place meanings in an urban park. Journal of Environmental Psychology, 36, 291-304.

Manzo, L.C. 2005. For better or worse: Exploring multiple dimensions of place meaning. Journal of Environmental Psychology, 25(1), 67-86.

Mercer, C. 2010. A global view: The cultural turn in urban planning. in G. Baeker, (ed.), Rediscovering the wealth of places: a municipal cultural planning handbook for Canadian communities, St Thomas, Ontario, Municipal World Inc.

Monk, G.; Winslade, J.; Sinclair, S. 2008. New horizons in multicultural counseling, USA: sage publications.

Morse-Kahn, D. 2011. History as a cultural resource. in King, T. F. (ed.), A companion to cultural resource management, Blackwell.

Norberg-Shulz, C. 2012. Architectur: presence, language, place. Translated by A. Seyed Ahmadian. Tehran: Publishing Architect. [In Persian]

Pakzad, J. 2018. An intellectual history of urbanism. Tehran: Shahidi. [In Persian]

Parsa, M. 2010. New general psychology. Tehran: Besat. [In Persian]

Parvaneh, M. 2013. Design of urban squares with the approach of instilling a sense of place (a case of Rasht Square). Master Thesis in Urban Design, Guilan University. [In Persian]

Perley, B.C. 2011. Language as an integrated cultural resource. in King, T. F. (ed.), A companion to cultural resource management, Blackwell.

Peters, K. 2010. Being together in urban parks: Connecting public space, leisure, and diversity. Leisure Sciences, 32, 418433.

Rahbarnia, Z.; Mehrizi Thani, S. 2008. Explain the boundaries between realistic, abstract, and abstract photography. Fine Arts 33, 85-94. [In Persian]

Rapoport, A. 1990. The meaning of the built environment, a nonverbal communication approach. USA: The University of Arizona Press

Rapoport, A. 2013. The meaning of the built environment: a nonverbal communication approach. Translated by F. Habib. Tehran: Urban Processing and Planning. [In Persian]

Relph, E. C. 1976. Place and placelessness. London: Pion Limited.

Rennit, P., \& Maikov, K. 2015. Perceived restoration scale method turned into (used as the) evaluation tool for parks and open green spaces, using Tartu city parks as an example. City, Territory and Architecture, 2(6), 1-11.

Rezazadeh, R. 2004. Investigating the role of architecture in associating meanings and conveying concepts, Fine Arts 18, 3748. [In Persian]

Salehi Amiri, S.R. 2017. Cultural concepts and theories. Tehran: Qoqnus. [In Persian]

Sattari, J. 2001. Culture: In the statelessness of culture, in a conversation with Ali Dehbashi. [In Persian]

Sheibani, S. 1970. Some definitions of culture, Journal of Culture and Life 2, 115-121. [In Persian]

Smith, D.W., \& Mclntyre, R. 1982. Husserl and intentionality: A study of mind, meaning, and language. Springer.

Stevenson, D. 2005. Cultural planning in Australia: texts and contexts, The Journal of Arts Management, Law, and Society, $35(1), 36-48$

Stewart, W. 2008. Place meanings in stories of lived experience. in Kruger, L.E.; Hall, T.E.; \& Stiefel, M.C. (ed.). Understanding concepts of place in recreation research and management. Portland, US Department of Agriculture, Forest Service, Pacific Northwest Research Station.

Tylor, E. 1871. Primitive Culture: Research into the Development of Mythology, Philosophy, Religion, Art, and Custum. London: John Murray.

Williams, R. 1961. The long revolution. Chatto \& Windus.

Willow, A.J. 2011. Culturally significant natural resources: Where nature and culture meet. in King, T.F. (ed.), A companion to cultural resource management. Blackwell.

Worpole, K., Greenhalgh, L. 1995. Park life: urban parks and social renewal. UK: Demos.

Wynveen, C. J., Kyle, G.T., \& Sutton, S.G. 2010. Place meanings ascribed to marine settings: The case of the Great Barrier Reef Marine Park. Leisure Sciences, 32, 270-287.

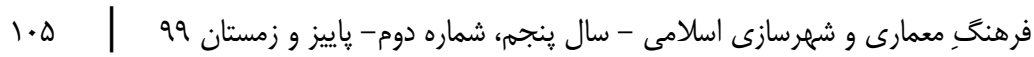


Yazdani, N. 2017. Migration, landscape, and culture: urban parks and Iranian immigrants in Melbourne. Ph.D. Thesis, Deakin University.

Zerlang, M. 2005. The cultural turn in contemporary urban planning. in Østergaard K. ed, Cultural Planning, The Royal Danish Academy of Fine Arts School of Architecture.

Zhou, M., Huang, L., Shen, Z. 2018. Community renewal strategy from the perspective of cultural planning: A case study on Caohuajie community in Chongqing International review for spatial planning and sustainable development A: planning strategies and design concepts 6(1). 